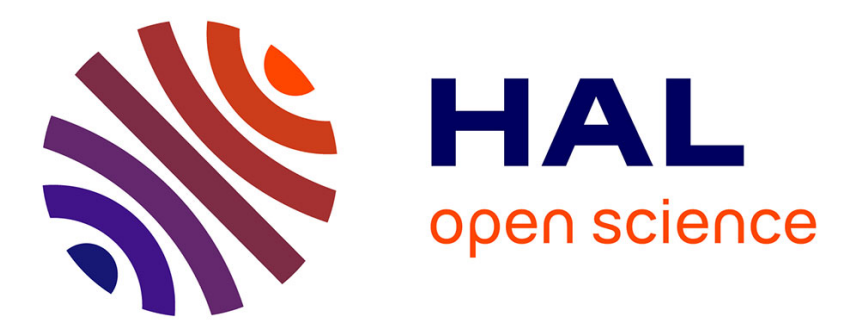

\title{
Metamagnetic Transitions versus Magnetocrystalline Anisotropy in Two Cobalt Arsenates with 1D Co 2+ Chains
}

Bastien Leclercq, Houria Kabbour, Françoise Damay, Claire Colin, Alain Pautrat, Ángel M Arévalo-López, Olivier Mentré

\section{To cite this version:}

Bastien Leclercq, Houria Kabbour, Françoise Damay, Claire Colin, Alain Pautrat, et al.. Metamagnetic Transitions versus Magnetocrystalline Anisotropy in Two Cobalt Arsenates with 1D Co 2+ Chains. Inorganic Chemistry, 2019, 58 (19), pp.12609-12617. 10.1021/acs.inorgchem.9b01303 . hal02295933

\section{HAL Id: hal-02295933 \\ https: / hal.univ-lille.fr/hal-02295933}

Submitted on 24 Sep 2019

HAL is a multi-disciplinary open access archive for the deposit and dissemination of scientific research documents, whether they are published or not. The documents may come from teaching and research institutions in France or abroad, or from public or private research centers.
L'archive ouverte pluridisciplinaire HAL, est destinée au dépôt et à la diffusion de documents scientifiques de niveau recherche, publiés ou non, émanant des établissements d'enseignement et de recherche français ou étrangers, des laboratoires publics ou privés. 


\title{
Metamagnetic transitions versus magnetocrystalline anisotropy in two cobalt arsenates with 1D $\mathrm{Co}^{2+}$ chains
}

\author{
Bastien Leclercq ${ }^{\alpha}$, Houria Kabbour ${ }^{\alpha}$, Françoise Damay ${ }^{\prime}$, Claire V. Colin ${ }^{\delta}$, \\ Alain Pautrat ${ }^{\beta}$, Angel M. Arevalo-Lopez ${ }^{\alpha}$, Olivier Mentré ${ }^{\alpha, *}$ \\ ${ }^{\alpha}$ UCCS, UMR-CNRS 8181, Université Lille-ENSCL, Avenue Mendeleiev, 59655 Villeneuve d'Ascq, France \\ ${ }^{\beta}$ Laboratoire CRISTMAT, UMR 6508-CNRS, ENSICAEN, 6 Bd. Du Maréchal Juin, 14000 Caen, France \\ $\gamma$ Laboratoire Léon Brillouin, UMR12-CNRS, CEA Saclay, Bât. 563, 91191 Gif-Sur-Yvette, France \\ ${ }^{\delta}$ Institut NEEL, CNRS/UGA UPR2940, 25 rue des Martyrs, 38042 Grenoble, France. \\ *Corresponding author: olivier.mentre@ensc-lille.fr
}

\begin{abstract}
We have investigated two original hydrated cobalt arsenates based on $\mathrm{Co}^{2+}$ octahedral edgesharing chains. Their different magnetocrystalline anisotropies induce different types of metamagnetic transition, spin-flop versus spin-flip. In both compounds, a strong local anisotropy (Ising spins) is favored by the spin-orbit coupling present in the $\mathrm{CoO}_{6}$ octahedra while ferromagnetic (FM) exchanges predominate in the chains. $\mathrm{Co}_{2}\left(\mathrm{As}_{2} \mathrm{O}_{7}\right), 2 \mathrm{H}_{2} \mathrm{O}$ (1) orders antiferromagnetically below $\mathrm{T}_{\mathrm{N}}=6.7 \mathrm{~K}$. The magnetic structure is a non-collinear antiferromagnetic spin arrangement along the zigzag chains with DFT calculations imply frustrated chains and weakened anisotropy. A metamagnetic transition suggests a spin-flop process above $\mu_{0} \mathrm{H}=3.2 \mathrm{~T}$. On the contrary, $\mathrm{BaCo}_{2} \mathrm{As}_{2} \mathrm{O}_{8} \cdot 2 \mathrm{H}_{2} \mathrm{O}$ (2) linear chains are arranged in disconnected layers, with only inter-chain ferromagnetic exchanges and therefore increasing its magnetocrystalline anisotropy. The magnetic structure is collinear with a magnetic easy axis that allows a spin-flop to a sharp spin-flip transition below $\mathrm{T}_{\mathrm{N}}=15.1 \mathrm{~K}$ and above $\mu_{0} \mathrm{H}=6.2 \mathrm{~T}$.
\end{abstract}




\section{INTRODUCTION}

The large spin orbit coupling and single-ion anisotropy of $\mathrm{Co}^{2+}$ is beneficial to design Isingferromagnetic one-dimensional (1D) units in chains. Clearly in the field of hybrid molecular magnets, this ion plays a central role because strong magnetocrystalline anisotropy together with magnetic easy-axis are required for realizing single chain magnets, i.e. systems with strongly decoupled 1D-units and slow spin dynamics. ${ }^{1}$ In oxides or related systems, edge sharing connection between $\mathrm{CoO}_{6}$ octahedral units assess ferromagnetic exchanges, leading to low-D magnets (ferro, ferri or canted chains or layers) with various exotic phenomena such as quantum phase transition $\mathrm{CoNb}_{2} \mathrm{O}_{6},{ }^{2} 1 / 3$ magnetization plateau in $\mathrm{CoV}_{2} \mathrm{O}_{6}{ }^{3,4}$ or spin density wave transition in presence of magnetic field in $\mathrm{BaCo}_{2} \mathrm{~V}_{2} \mathrm{O}_{8} .{ }^{5}$ More generally, the realization of metamagnetic transitions between FM units involves weak magnetic interactions between them where the choice of well-adapted chemical separators is crucial. The literature, including work on original low-D magnets prepared in our group, suggests that the association of both large counter-cations and oxo-anions such as $\mathrm{XO}_{4}$ groups $(\mathrm{X}=\mathrm{P}, \mathrm{V}, \mathrm{As})$ favors an efficient template for low-D units. For instance, the various phases observed in the $\mathrm{BaCo}_{2}\left(\mathrm{PO}_{4}\right)_{2}$ phase diagram are largely dominated by $2 \mathrm{D}$-structural and magnetic topologies, in which phosphate and $\mathrm{Ba}^{2+}$ play the role of spacers. ${ }^{6}$ We have also evidenced magnetization plateaus in $\mathrm{BaCo}\left(\mathrm{X}_{2} \mathrm{O}_{7}\right)$ due to $1 \mathrm{D}$-chains of ferromagnetic $\mathrm{Co}^{2+}$ dimers in- and between- which the bending of $\mathrm{X}_{2} \mathrm{O}_{7}$ respects a modulated sequence, bringing a distribution of frustration in the crystal. ${ }^{7}$ One should also recall the role of ${ }_{\infty}\left[\mathrm{AsO}_{2}\right]^{-}$chains (or catena-arsenites) able to separate $1 \mathrm{D}$ chains in $\mathrm{BaCo}_{2}\left(\mathrm{As}_{3} \mathrm{O}_{6}\right)_{2} \cdot 2\left(\mathrm{H}_{2} \mathrm{O}\right)$ at the origin of low spin dynamics in this system, a rare behavior for purely inorganic materials. ${ }^{8}$ These results and renewed interest for inorganic low-D magnets (see the Ising $\mathrm{FM} \mathrm{BaFe}_{2}\left(\mathrm{PO}_{4}\right)_{2}$ phase ${ }^{9}$ ) led us to re-examine several chemical systems. In this paper, the prospection for novel barium cobalt arsenates yields the preparation of the novel $\mathrm{BaCo}_{2} \mathrm{As}_{2} \mathrm{O}_{8} .2 \mathrm{H}_{2} \mathrm{O}$ (2) compound, obtained as a by-product of the highly stable $\mathrm{Co}_{2}\left(\mathrm{As}_{2} \mathrm{O}_{7}\right) \cdot 2 \mathrm{H}_{2} \mathrm{O}$ phase (1). Although this latter was already reported, no magnetic characterization was performed up to day. ${ }^{10}$ Here we show in (1) and (2) the efficient role of $\mathrm{Ba}^{2+}, \mathrm{AsO}_{4}, \mathrm{As}_{2} \mathrm{O}_{7}$, and water molecules spacers to minimize the magnetic interactions between edge sharing 1D-chains, promoting two novel realizations of metamagnetic transitions. When applying a magnetic field it tends to rotate the magnetization perpendicular to the applied field. Two cases may occur spinflop/spinflip depending on the large or weakest magnetocrystalline anisotropy. Our tandem of compounds gives nice examples for the topological occurrence of these two antagonist transitions. The synthesis, crystal chemistry, thermal stability and magnetic characterization are discussed in the prism of those transitions.

\section{EXPERIMENTAL SECTION}

\section{Synthesis}

$\mathrm{Co}_{2} \mathrm{As}_{2} \mathrm{O}_{7} .2 \mathrm{H}_{2} \mathrm{O}$ (1) was originally prepared by hydrothermal treatment of a mixture of $\mathrm{Co}(\mathrm{OH})_{2}$ and $\mathrm{H}_{3} \mathrm{AsO}_{4} / \mathrm{As}_{2} \mathrm{O}_{3}$ in acidified water. ${ }^{10}$ During the exploration of barium cobalt arsenates, we re-prepared the single material using $\mathrm{BaCO}_{3}, \mathrm{CoCl}_{2} .6 \mathrm{H}_{2} \mathrm{O}$ and $\mathrm{As}_{2} \mathrm{O}_{5} .1 \mathrm{H}_{2} \mathrm{O}$ in $1: 1: 2.5$ ratio (total mass $=3 \mathrm{~g}$ ) with $\sim 10 \mathrm{~mL}$ of distilled water in a $23 \mathrm{~mL}$ Teflon Lined autoclave, subsequently heated to $483 \mathrm{~K}$ for $76 \mathrm{~h}$ and then cooled down to room temperature in a period of 75h. The resulting product composed of pink needle like crystals of $\mathrm{Co}_{2} \mathrm{As}_{2} \mathrm{O}_{7} \cdot 2 \mathrm{H}_{2} \mathrm{O}$ (up to $0.3 \mathrm{~mm}$ long) was filtered, washed twice with hot water, rinsed with ethanol and dried in air. Changing the initial ratio between the reactants leads to an additional second phase of formula $\mathrm{BaCo}_{2} \mathrm{As}_{2} \mathrm{O}_{8} .2 \mathrm{H}_{2} \mathrm{O}$ (2) as orange hexagonal plates (up to $0.2 \mathrm{~mm}$ long), that we have not been 
able to prepare exempt of the cobalt diarsenate hydrate. At best, the 1:1:1 ratio between $\mathrm{BaCO}_{3}$, $\mathrm{CoCl}_{2} .6 \mathrm{H}_{2} \mathrm{O}$ and $\mathrm{As}_{2} \mathrm{O}_{5} .1 \mathrm{H}_{2} \mathrm{O}$ gives (1)/(2) in $\sim 77 / 23$ proportion.

\section{Single-Crystal X-Ray Diffraction (XRD)}

$\mathrm{Co}_{2} \mathrm{As}_{2} \mathrm{O}_{7} .2 \mathrm{H}_{2} \mathrm{O}$ room-temperature single crystal (X-Ray Diffraction) (XRD) was carried out on a Bruker X8 diffractometer using Ag-K $\alpha$ radiation, with an APEX detector and a graphite monochromator. $\mathrm{BaCo}_{2} \mathrm{As}_{2} \mathrm{O}_{8} \cdot 2 \mathrm{H}_{2} \mathrm{O}$ room-temperature single crystal XRD was carried out on a DUO-Bruker SMART diffractometer using Mo-K $\alpha$ radiation, also with an APEX detector and a graphite monochromator. In these two cases, intensities were extracted and corrected from the Lorentz-polarization factor through the SAINT program. A multiscan absorption correction was applied using SADABS. Structures were solved using Superflip and refined using JANA2006. ${ }^{11}$

\section{Magnetic Measurements}

Magnetic data and heat capacities were measured on a Physical Property Measurement System (PPMS) Dynacool (9T) system from Quantum Design, using the grinded single phase polycrystalline phase for $\mathrm{Co}_{2} \mathrm{As}_{2} \mathrm{O}_{7} \cdot 2 \mathrm{H}_{2} \mathrm{O}$ and a batch of isolated crystals for $\mathrm{BaCo}_{2} \mathrm{As}_{2} \mathrm{O}_{8} \cdot 2 \mathrm{H}_{2} \mathrm{O}$. We performed typical measurements using zero field cooling (ZFC) and field cooling (FC) procedures under various fields. Magnetization versus $\mathrm{H}$ was measured between -9 and 9T at various temperatures. Specific heat measurements were carried out with a PPMS using either the material (1) pressed into a pellet and deposited crystals for (2) at different magnetic fields between 0 and 9T.

\section{Thermal Analysis}

Thermogravimetric analysis (TGA) were carried out on a thermoanalyzer Setsys Evolution SETARAM device under air atmosphere using a ramp of $5^{\circ} \mathrm{C} / \mathrm{min}$ up to $600^{\circ} \mathrm{C}$ on single phase polycrystalline sample of (1). Differential thermal analysis (DTA) were carried out on the same device under air, using a ramp of $2^{\circ} \mathrm{C} / \mathrm{min}$ up to $700^{\circ} \mathrm{C}$ on a grinded sample containing a mixture $(1) /(2)$ in $c a .77 / 23$ ratio.

High temperature X-ray measurements (HTXRD) were performed using a D8 Advance Bruker instrument equipped with an XRK900 chamber under flowing air, on the (1)/(2) mixture. Each powder pattern was recorded in the range $10-80^{\circ}(2 \theta)$ (step $\Delta \mathrm{T}=50^{\circ} \mathrm{C}, 30 \mathrm{~min}$ per scan) from room temperature up to $800^{\circ} \mathrm{C}$.

\section{Density Functional Theory (DFT) Calculations - Computational Methods}

DFT calculations were carried using the Vienna ab initio simulation package (VASP) ${ }^{12}$ by employing the projector augmented wave $(\mathrm{PAW})^{13}$ method and the generalized gradient approximation of Perdew, Burke and Ernzerhof (PBE) for the exchange-correlation functionals. ${ }^{14} \mathrm{GGA}+U$ calculations were employed with $\mathrm{U}=5$ to $7 \mathrm{eV}$ to account for the strong coulomb repulsion related to $d$ orbitals of Co atoms. The plane wave cutoff energies of $400 \mathrm{eV}$ and the threshold of self-consistent-field energy convergence of $10^{-6} \mathrm{eV}$ were used, with 82 (22) $k$ points in the irreducible Brillouin Zone for $\mathrm{BaCo}_{2} \mathrm{As}_{2} \mathrm{O}_{8} .2 \mathrm{H}_{2} \mathrm{O}\left(\mathrm{Co}_{2} \mathrm{As}_{2} \mathrm{O}_{7} .2 \mathrm{H}_{2} \mathrm{O}\right)$. The energies of selected ordered spin states can be expressed using the spin Hamiltonian, $\widehat{H}=$ $-\sum_{i<j} J_{i j} \hat{S}_{i} \cdot \hat{S}_{j}$, where $\mathrm{J}_{i j}$ corresponds to the exchange parameters between the spin sites $i$ and $j$, extracted by equating the relative energies of the selected ordered magnetic states to the corresponding energies determined from the GGA+U calculations, see S5 ; Figure S5c and Figure S5f for the details of the selected magnetic configurations.

\section{IR and UV-visible Spectroscopies}

Infrared spectroscopy (IR) measurements were performed on a Perkin Elmer Spectrum 2 
device, equipped with a diamond attenuated total reflectance (ATR) accessory. Samples (batch of sorted single crystal) were measured between $4000 \& 400 \mathrm{~cm}^{-1}$. No ATR corrections were applied on the spectrum.

UV-visible measurement was performed on a Perkin Elmer Precisely Lambda 650 Spectrometer devices, using an STD Detector module \& HARRICK Praying Mantis Sampling Kit. The measurement was done between $900 \& 250 \mathrm{~nm}$ for single phase (1) sample.

\section{Scanning Electron Microscope (SEM)}

Energy-dispersive X-ray spectroscopy (EDS) analysis were performed on a small amount of crystals placed on a carbon tape and introduced in a field-emission gun Scanning Electron Microscope (SEM) HITACHI S4700 device equipped with and Energy-dispersive X-Ray detector, operating at $20 \mathrm{kV}$ electron beam energy. The EDS analysis is given from the average of several different points acquisitions.

\section{Neutron powder diffraction (NPD)}

Neutron powder diffraction (NPD) experiments were carried out on the G4.1 beamline of the LLB (Laboratoire Léon Brillouin, Saclay, France) using $\lambda=2.43 \AA$ in the $2 \theta$ range $5-85^{\circ}$ at 2 $\mathrm{K}, 12 \mathrm{~K}$ and $22 \mathrm{~K}$, on grinded polycrystalline sample containing $\mathrm{Co}_{2} \mathrm{As}_{2} \mathrm{O}_{7} .2 \mathrm{H}_{2} \mathrm{O}$ and $\mathrm{BaCo}_{2} \mathrm{As}_{2} \mathrm{O}_{8} .2 \mathrm{H}_{2} \mathrm{O}$ in $75 / 25$ ratio into a vanadium cylinder (one sample due to experiment time allocated reasons). The NPD-based refinements were carried out using the FULLPROF program. ${ }^{15}$

\section{RESULTS AND DISCUSSION}

\section{Structural analysis and spectroscopic characterization}

Compound 1: As-prepared in a batch containing the two phases (Figure 1a) crystals of (1) and (2) are shown in Figure 1b,c. Dealing with (1), the diphosphate and diarsenate are isomorph compounds. ${ }^{10}$ Their framework was already described as infinite zigzag chains of edge-sharing $\mathrm{CoO}_{6}$, octahedra linked by $\mathrm{As}_{2} \mathrm{O}_{7}$ groups to form a three-dimensional architecture which consists of intersecting tunnels. ${ }^{10}$ The zigzag chains run parallel to the [10-1] direction with alternation of two independent $\mathrm{ColO}_{6}$ and $\mathrm{Co}_{2} \mathrm{O}_{6}$ octahedra, as shown in Figure $1 \mathrm{~d}$. The 3D arrangement between the chains is shown in Figure 1e. Our single crystal analysis was consistent with the previous reports (see S8 ; Figure S8a),${ }^{10,16}$ hydrogens have been located on Fourier-difference maps around $\mathrm{O} 7$ and $\mathrm{O} 8$, leading to two independent water molecules $\mathrm{H} 1 \mathrm{H} 4 \mathrm{O} 7$ and $\mathrm{H} 2 \mathrm{H} 3 \mathrm{O} 8$. The atomic coordinates used for DFT calculations and bond distances are listed in the SI (S1:Tables S1a, b, c). The refined monoclinic lattice constants are $a=$ 6.5314(8) $\AA, b=14.207(2) \AA, c=7.6157(13) \AA$, and $\beta=94.735(7)^{\circ}$, space group $\mathrm{P} 2{ }_{1} / n\left(\mathrm{R}_{\mathrm{obs}}\right.$ $=4.86 \%$ ). Its magnetic properties were preliminary reported by means of susceptibility measurement only. Magnetic ordering below $\mathrm{T}_{\mathrm{N}} \sim 10 \mathrm{~K}$ was announced. However, the existence of $\mathrm{Co}^{2+}$ chains encouraged us to deepen this study. For instance, one notes the strong analogy between the magnetic units in $\mathrm{Co}_{2} \mathrm{As}_{2} \mathrm{O}_{7} .2 \mathrm{H}_{2} \mathrm{O}$ and those of $\mathrm{BaCo}_{2}\left(\mathrm{VO}_{4}\right)_{2}$, a nice example of a quasi-one-dimensional quantum spin system with a transition into a spin density wave under applied field. ${ }^{17}$ The main difference between the edge-sharing $\mathrm{Co}^{2+}$ octahedral 1D-units consists of the cis/trans connection along the chains. In $\mathrm{Co}_{2} \mathrm{As}_{2} \mathrm{O}_{7} \cdot 2 \mathrm{H}_{2} \mathrm{O}$, the two independent $\mathrm{CoO}_{6}$ have respectively two trans corner-shared neighbors (Co1) and two cis ones (Co2) leading to "flat" zigzag chains, with Co1-Co2 distances of $3.25 \AA$ and Co1-O-Co2 angles of $\sim 100^{\circ}$. On the opposite, in $\mathrm{BaCo}_{2} \mathrm{~V}_{2} \mathrm{O}_{8}$ the zigzag chains are staggered due to cis edge-connections only between all equivalent $\mathrm{CoO}_{6}$ leading to $\mathrm{Co}$-Co distances of $2.91 \AA$ with an angle Co-O-Co of $\sim 87.5^{\circ}$, Figure 1f. However, the degree of "magnetic" disconnection is expected to be very different in the two phases dealing with $\mathrm{VO}_{4}$ against $\mathrm{As}_{2} \mathrm{O}_{7}$ groups. Indeed, the arsenates are known as less efficient magnetic links due to As-O covalency, as clearly shown for instance in 
the $\mathrm{Pb}_{2}(\mathrm{VO})\left(\mathrm{XO}_{4}\right)_{2}$ series with $\mathrm{X}=\mathrm{As}$ and $\mathrm{V} .{ }^{18}$ Thus, in the context of our magnetic analysis the 1D-magnetic units of $\mathrm{Co}_{2} \mathrm{As}_{2} \mathrm{O}_{7} .2 \mathrm{H}_{2} \mathrm{O}$ possess structural and chemical pre-request for more pronounced isolated magnetic units. The absorption and the IR spectra for $\mathrm{Co}_{2} \mathrm{As}_{2} \mathrm{O}_{7} \cdot 2 \mathrm{H}_{2} \mathrm{O}$ crystals (Figure $2 \mathrm{a}$ and Figure $2 \mathrm{~b}$, respectively) show a significant absorption around $2 \mathrm{eV}$ assigned to the bandgap. At higher energy a strong absorbance peak centered around $550 \mathrm{~nm}$ (green absorption) validates the magenta color of the sample.

The vibration bands were assigned following the attribution for $\mathrm{Mn}_{2} \mathrm{As}_{2} \mathrm{O}_{7} \cdot 2 \mathrm{H}_{2} \mathrm{O} .{ }^{19}$ The presence of water in the crystal structure is confirmed by stretching modes at $3410 / 3200$ and bending vibrations bands at $1632 \mathrm{~cm}^{-1}$. The spectrum also evidences the $\mathrm{CoO}_{4}$ bending at 630 , $\mathrm{AsO}_{3}\left(-\mathrm{O}-\mathrm{AsO}_{3}\right)$ stretching at $815 / 760 / 580$ and bending at $400 \mathrm{~cm}^{-1}$. The weak band at $1480 \mathrm{~cm}^{-}$ ${ }^{1}$ corresponds to in plane deformation of O-H-O interaction between octahedral corners. ${ }^{20}$

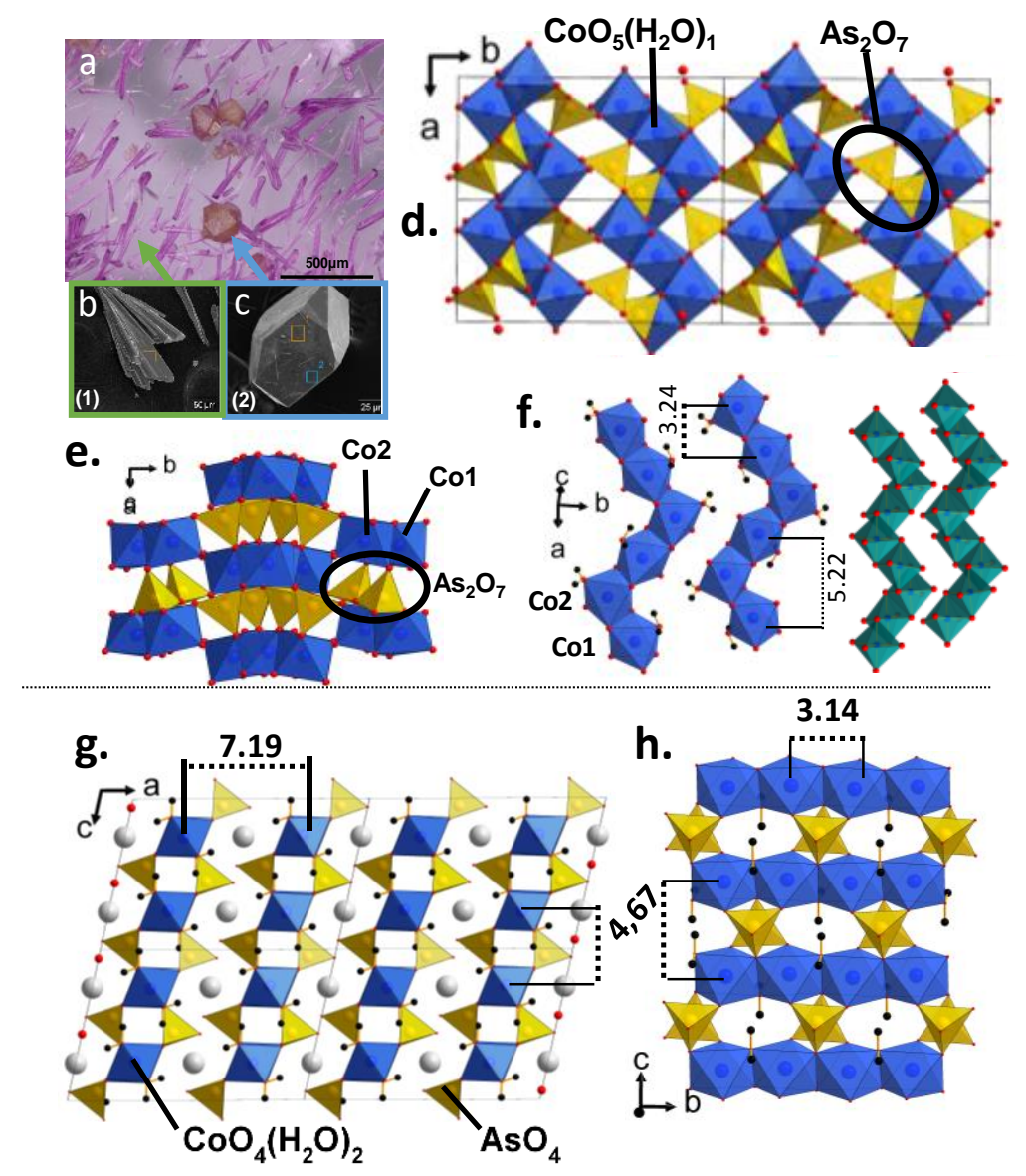

Figure 1 : (a) Sample containing (b) pink needle like crystals of $\mathrm{Co}_{2} \mathrm{As}_{2} \mathrm{O}_{7} .2 \mathrm{H}_{2} \mathrm{O}$ and (c) orange prism of $\mathrm{BaCo}_{2} \mathrm{As}_{2} \mathrm{O}_{8} .2 \mathrm{H}_{2} \mathrm{O}$. $\mathrm{Co}_{2} \mathrm{As}_{2} \mathrm{O}_{7} .2 \mathrm{H}_{2} \mathrm{O}$ structure describing (d) the infinite $\mathrm{CoO}_{6}$ zigzag chains and (e) the $3 \mathrm{D}$ arrangement between the chains. (f) $\mathrm{CO}_{2} \mathrm{As}_{2} \mathrm{O}_{7} \mathrm{O}_{2} \mathrm{H}_{2} \mathrm{O}$ (blue) zigzag chains in comparison with the one from $\mathrm{BaCo}_{2} \mathrm{~V}_{2} \mathrm{O}_{8}$ (green). (g) $\mathrm{BaCo}_{2} \mathrm{As}_{2} \mathrm{O}_{8} 2 \mathrm{H}_{2} \mathrm{O}_{\text {structure }}$ describing $3 D$ representation and (h) $2 D$ stacking of the chains in the layer.

Compound 2 : SEM images of the corresponding crystals are shown in Fig.1c. Compound (2) has a layered crystal structure analog to the $\mathrm{SrNi}_{2}\left(\mathrm{PO}_{4}\right) 2.2 \mathrm{H}_{2} \mathrm{O}$ compound, ${ }^{21}$ but due to $\mathrm{Ba}^{2+}$ $v s . \mathrm{Sr}^{2+}$ size effect the stacking between the layers is slightly modified, such that the strontium compound crystallizes in a half volume (V/2) unit cell with the $\mathrm{C} 2 / \mathrm{m}$ space group (see $\mathrm{S} 8$; Figure S8). ${ }^{21}$ Thus, the compound (2) is structurally original and is monoclinic, $\mathrm{C} 2 / c$ space group, with unit cell parameters $a=14.4555(10) \AA, b=6.2795(4) \AA, c=9.3370(6) \AA$ and $\beta=$ $102.702(3){ }^{\circ}\left(\mathrm{R}_{\mathrm{obs}}=3.38 \% / / \mathrm{wR}_{\mathrm{obs}}=4.23 \%\right)$. Collection and refinement parameters are listed 
Table1. The coordinates and selected bond distances are given in the SI (S2 ; Tables S2a, b, c, d). The crystal structure consists of linear chains of $\mathrm{Co}^{2+} \mathrm{O}_{6}$ edge-sharing octahedra running parallel to the $b$ axis, see Figure $1 \mathrm{~g}$. In the chains, the Co-Co distance is $3.14 \AA$. The chains are linked through $\mathrm{As}^{5+} \mathrm{O}_{4}$ tetrahedra building up layers parallel to the $(b c)$ plane, see Figure $1 \mathrm{~h}$. The shortest Co-Co inter-chain distance is $4.69 \AA$. The stacking of the layers occurs along the $a$ axis (separated by $\mathrm{Ba}^{2+}$ by $c a$. $7.2 \AA$, i.e. $a / 2$ ) leading to the $3 \mathrm{D}$ representation of the structure given in Figure 1g. The oxygen $\mathrm{O} 4$ form water molecules whose presence was proved by infrared spectroscopy and thermal analysis. Hydrogen atoms were located using Fourierdifference maps. They alternate with the arsenate along the chain axis, Figure $1 \mathrm{~h}$.

The IR spectra for $\mathrm{BaCo}_{2} \mathrm{As}_{2} \mathrm{O}_{8} .2 \mathrm{H}_{2} \mathrm{O}$ is show in red in Figure 2b. The presence of water in the crystal structure is confirmed by stretching vibrations bands at 3733 / $3645 / 3563$ and bending vibrations bands at $1560 \mathrm{~cm}^{-1}$. The $\mathrm{CoO} 4$ bending, $\mathrm{AsO}_{4}$ stretching and $\mathrm{AsO}_{4}$ bending modes appear at $640,960 / 880 / 750$ and $460 \mathrm{~cm}^{-1}$ respectively. ${ }^{19}$

For both compounds, the refined formula are in good agreement with the EDS analyzes, i.e. giving averaged ratio $\mathrm{As} / \mathrm{Co}$ of 1.1/0.9 for compound 1 and $\mathrm{Ba} / \mathrm{Co} / \mathrm{As}$ ratio of $1 / 1.9 / 1.85$ for compound 2 (S3 : Figure S3a,b).

Table 1 : Crystal Data and Refinement Characteristics for $\mathrm{BaCO}_{2} \mathrm{As}_{2} \mathrm{O}_{8} \cdot 2 \mathrm{H}_{2} \mathrm{O}$ at Room Temperature.

\begin{tabular}{|c|c|}
\hline \multicolumn{2}{|c|}{ Crystal Data $(\mathrm{T}=293 \mathrm{~K})$} \\
\hline Formula & $\mathrm{BaCo}_{2} \mathrm{As}_{2} \mathrm{O}_{8} \cdot 2 \mathrm{H}_{2} \mathrm{O}$ \\
\hline Molar weight $(\mathrm{g} / \mathrm{mol})$ & 569,07 \\
\hline Symmetry & Monoclinic \\
\hline Space group & C $12 / \mathrm{c} 1(15)$ \\
\hline Unit cell $(\AA)$ and angle $\left({ }^{\circ}\right)$ & $\mathrm{a}=14.4555(10)$ \\
\hline & $\mathrm{b}=6,2795(4)$ \\
\hline & $c=9.3370(6)$ \\
\hline & $\beta=102.702(3)$ \\
\hline Volume $\left(\AA^{3}\right)$ & $826.81(9)$ \\
\hline $\mathrm{Z}$ & 4 \\
\hline \multicolumn{2}{|c|}{ Data collection } \\
\hline Equipment & Bruker DUO \\
\hline$\lambda$ (Mo K $\alpha$ (graphite monochromator); $\AA$ ) & 0.71073 \\
\hline density calc. $\left(\mathrm{g} / \mathrm{cm}^{3}\right)$ & 4,57159 \\
\hline Color & orange \\
\hline$\theta(\min -\max )\left(^{\circ}\right)$ & $2,89-39,85$ \\
\hline$\mu(\mathrm{mm}-1 ;$ for $\lambda \mathrm{K} \alpha=0,71073 \AA)$ & 16,66 \\
\hline $\mathrm{R}_{\mathrm{int}}(\%)$ & 2,5 \\
\hline Recording reciprocal space & $-24 \leq \mathrm{h} \leq 25-10 \leq \mathrm{k} \leq 10 \quad-13 \leq 1 \leq 15$ \\
\hline Number of measured reflections & 12928 \\
\hline Number of independant reflections $(\mathrm{I}>3 \sigma(\mathrm{I})$ & $751 / 732$ \\
\hline Crystal dimension $(\mu \mathrm{m})$ & $80 * 50 * 35$ \\
\hline \multicolumn{2}{|c|}{ Refinement } \\
\hline Number of refined parameters & 78 \\
\hline Refinement method, program & Least square on $\mathrm{F}$ \\
\hline Weighting scheme & Unit \\
\hline $\mathrm{R} 1(\mathrm{~F})[\mathrm{I}>3 \sigma(\mathrm{I})] / \mathrm{R} 1\left(\mathrm{~F}^{2}\right)[$ All data, $\%]$ & $3,38 / 3,42$ \\
\hline $\mathrm{wR}^{2}\left(\mathrm{~F}^{2}\right)[\mathrm{I}>3 \sigma(\mathrm{I})] / \mathrm{wR} 2\left(\mathrm{~F}^{2}\right)$ [All data, \%] & $4,23 / 4,23$ \\
\hline GOF & 1,03 \\
\hline Max/min residual electronic density $\left(\mathrm{e}-/ \AA^{3}\right)$ & $1,79 /-1,31$ \\
\hline Refined extinction coefficient & 0.015973 \\
\hline
\end{tabular}



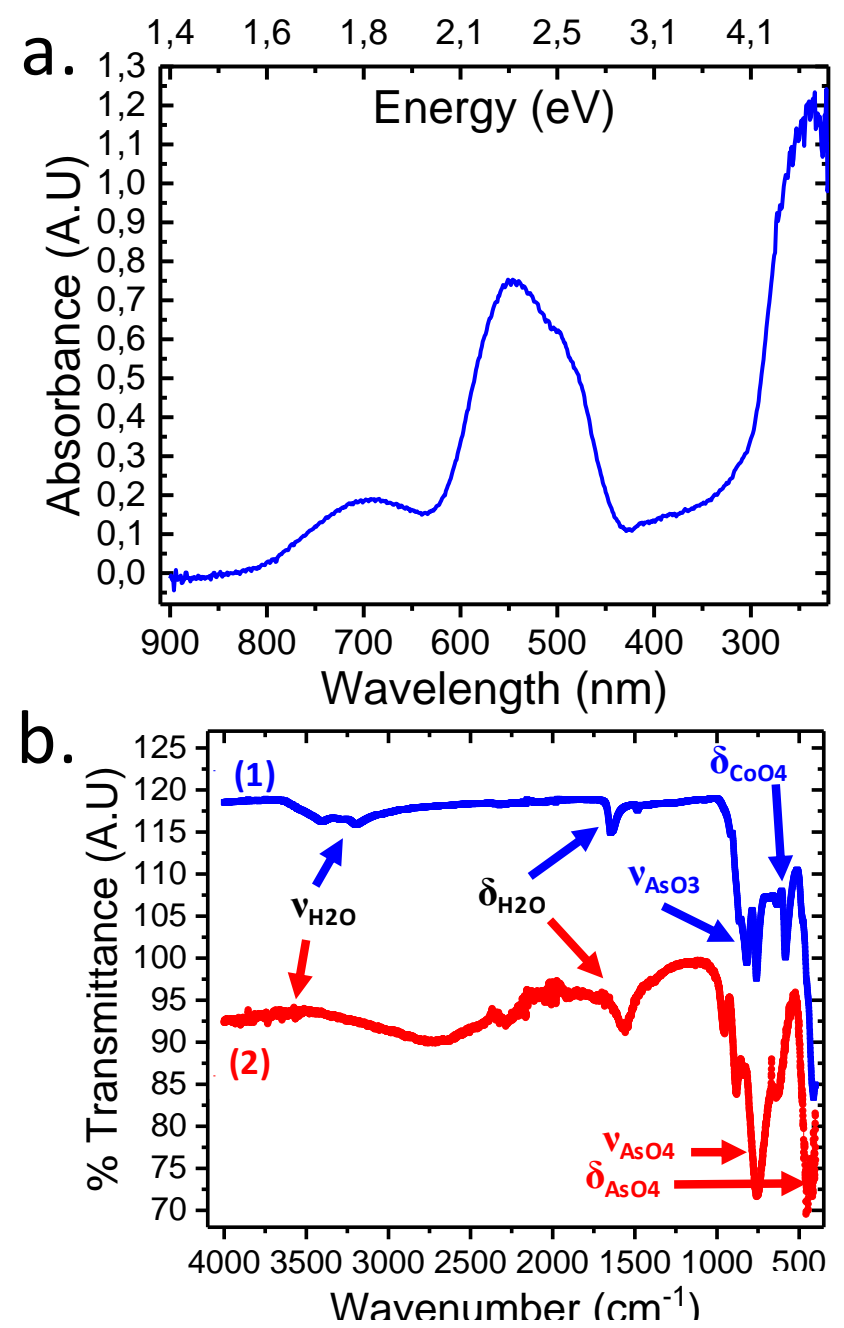

Figure 2: (a) Absorbance UV visible spectra for $\mathrm{CO}_{2} \mathrm{As}_{2} \mathrm{O}_{7} .2 \mathrm{H}_{2} \mathrm{O}$. (b) Infrared transmittance spectra for $\mathrm{Co}_{2} \mathrm{As}_{2} \mathrm{O}_{7} .2 \mathrm{H}_{2} \mathrm{O}$ (in blue) and $\mathrm{BaCo}_{2} \mathrm{As}_{2} \mathrm{O}_{8} 2 \mathrm{H}_{2} \mathrm{O}$ (in red) with highlighting of the main characteristic bands.

\section{Thermal stability}

Upon heating in air, $\mathrm{Co}_{2} \mathrm{As}_{2} \mathrm{O}_{7} .2 \mathrm{H}_{2} \mathrm{O}$ is stable until $445^{\circ} \mathrm{C}$, temperature at which the removal of the two independent water molecules occurs. The TGA performed on a single-phase batch (8.9 \% mass loss) agrees well with the removal of water molecules, Figure 3a. The high temperature XRD (HTXRD) shows that the hydrated phase transforms in a single stage into the high temperature monoclinic $\beta-\mathrm{Co}_{2} \mathrm{As}_{2} \mathrm{O}_{7}$, a thortveitite variant, Figure $3 \mathrm{~b} .{ }^{22}$ In this phase the $1 \mathrm{D}$-zigzag $\mathrm{Co}^{2+}$ chains are conserved but assembled into 2D-layers by extra edge sharing connection due to the water removal (see S4; figure S4a for the structure). In a further step, dealing with a mixed (1)/(2) batch, the dehydration of the latter minor phase is observed at $400^{\circ} \mathrm{C}$. The total mass loss ( $\mathrm{ca} .8 \%$ for the $1+2$ mixture) is consistent with a $77 \%(1) / 23 \%(2)$ molar ratio refined from diffraction data. The corresponding DTA plot shows the two subsequent transformations at 400 and $450{ }^{\circ} \mathrm{C}$, Figure $3 \mathrm{a}$. HTXRD shows the transformation of (2) into the rhombohedral anhydrous $\mathrm{BaCo}_{2} \mathrm{As}_{2} \mathrm{O}_{8}$, see Figure $3 b^{23}$ During the transformation, the linear edge-sharing chains are rearranged and condensed into honeycomb layers (see $\mathrm{S} 4$; Figure $\mathrm{S} 4 \mathrm{~b}$ for the structure), while the $2 \mathrm{D}$-character is conserved, $\mathrm{Ba}^{2+}$ and $\mathrm{AsO}_{4}$ present similar spacer groups in both the hydrated and anhydrous phases. 
a
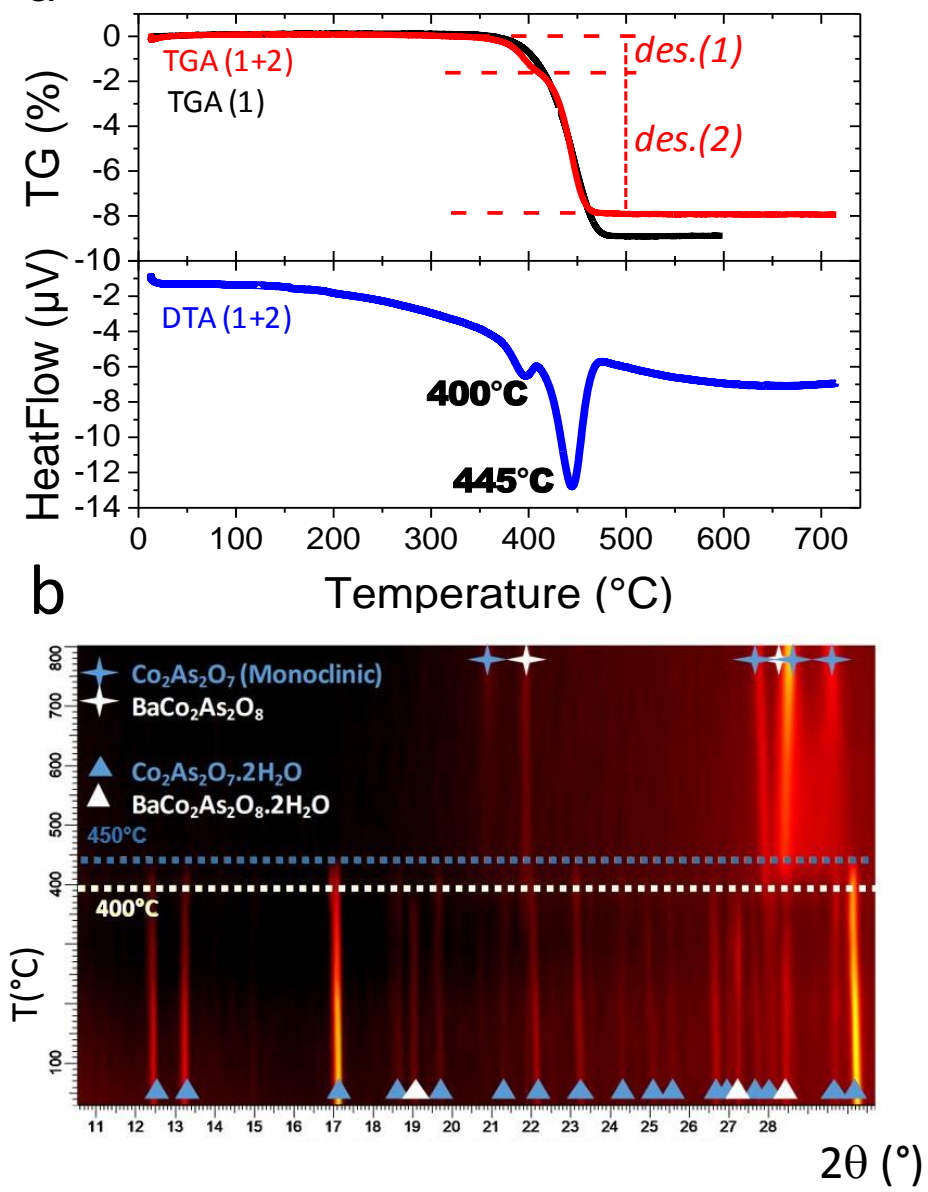

Figure 3: (a) TGA (in red) and DTA (in blue) curves for a sample containing 77\% $\mathrm{Co}_{2} \mathrm{As}_{2} \mathrm{O}_{7} .2 \mathrm{H}_{2} \mathrm{O}$ (1) and $23 \%$ $\mathrm{BaCO}_{2} \mathrm{As}_{2} \mathrm{O}_{8} \mathrm{H}_{2} \mathrm{O}$ (2) (des. stand for dehydration) (b) HTXRD evolution with evidence of the two transformations.

\section{Magnetic Properties}

Compound 1: The main identified exchanges in (1) are shown in Figure 4a, which pictures a zigzag chain with nearest-neighbors $(\mathrm{NN}) \mathrm{J}_{1}$ super-exchanges (SE). $\mathrm{J}_{1}$ results from two individual and nearly equal geometrical $\mathrm{Co} 1-\mathrm{Co} 2$ paths, which are approximated equal for sake of simplicity. As commonly observed in edge-sharing $\mathrm{CoO}_{6}$ connections, $\mathrm{J}_{1}$ is expected to be ferromagnetic. Next-nearest neighbors (NNN) diagonal super-super exchanges (SSE) labelled $\mathrm{J}_{\mathrm{d}}$ correspond to the Co2-Co2 interactions and are expected to compete with the ferromagnetism along the chains towards a reduced magnetocrystalline anisotropy. Finally, for simplification taking the criteria $\mathrm{d}_{\mathrm{Co}-\mathrm{Co}}<5.3 \AA$, three main interchain couplings have been identified, in the (ab) plane $\left(\mathrm{J}_{4}\right)$ and in a diagonal direction $\left(\mathrm{J}_{2,3}\right)$. Accurate geometrical parameters of the magnetic exchange paths are listed in S5 ; Table S5a.

In the simple cell used for our calculations, its was not possible to numerically isolate the $\mathrm{J}_{4}$ and $\mathrm{J}_{\mathrm{d}}$ values. However, the former was neglected based on geometrical arguments. Indeed SSE becomes stronger as the M-O..O-M contacts are coplanar, ${ }^{24}$ which is far from the case of $\mathrm{J}_{4}$ whose torsion angles Co-O-O-Co is close to $80^{\circ}$. This approximation was futher validated due to the similar geometrical characteristics and the very weak $\mathbf{J}_{2}$ value found for phase (2) (see below). 
The determination of the optimal $U$ value for the calculations on the phase (1) were rather complex and led to a small window around $\mathrm{U}=6 \mathrm{eV}$ as best describing the magnetic exchanges with respect to geometrical considerations see S5 ; Table S5b. Within the chain, $\mathrm{J}_{1}$ is found FM $(-5.63 \mathrm{~K})$ as expected, as well as $\mathrm{J}_{2}(-8.53 \mathrm{~K}), \mathrm{J}_{3}(0.91 \mathrm{~K})$ and $\mathrm{J}_{\mathrm{d}}(2.52 \mathrm{~K})$ are found weaker and AFM. This leads to dominating FM interactions as depicted by the calculated $\theta \mathrm{c}(=12.5 \mathrm{~K})$ in the mean field approximation $\left(\theta_{\mathrm{C}}=\Sigma_{\mathrm{i}} \mathrm{Z}_{\mathrm{i}} \mathrm{S}(\mathrm{S}+1) \mathrm{J}_{\mathrm{i}} / 3 \mathrm{~K}_{\mathrm{b}}\right)$, which contradicts the negative experimental value discussed later. Albeit the qualitatively reasonable set of $\mathrm{J}$ values, this reflects the complexity to model this system, e.g. see the non-collinear magnetic structure refined below. At least in the chain a frustrated situation is promoted by the FM $J_{1}$ and AFM $J_{d}$ interplay. Although misleading on the basis of Co-Co distances, similar $\mathrm{J} 2>\mathrm{J} 1$ hierachies are relatively common, see a drastic case in $\mathrm{Fe}_{2}\left(\mathrm{SeO}_{3}\right)_{3}$ and $\mathrm{Fe}_{2}\left(\mathrm{HPO}_{3}\right)_{3}{ }^{25}$ Plausibly the the Co-OCo angle of $c a$. $100^{\circ}$ along $\mathrm{J}_{1}$, is sufficiently shifted from $90^{\circ}$ to reduce the dominant FM contribution by adding AFM correlations.

The experimental magnetic susceptibility in the range $50-400 \mathrm{~K}$ follows a Curie-Weiss law with $\mathrm{C}=6.75 \mathrm{emu} . \mathrm{K} . \mathrm{mol}\left(\mu_{\mathrm{eff}}=5.2 \mu_{\mathrm{B}} / \mathrm{Co}\right)$ and $\theta_{\mathrm{CW}}=-16.9 \mathrm{~K}$; see Figure 5a. The effective moment is much above the spin-only value of $3.87 \mu_{\mathrm{B}}$ due to orbital contribution.

Edge sharing cobalt chains generally promote ferromagnetic coupling with strong local anisotropy due to spin-orbit coupling, so that negative Weiss temperature accounts for antiferromagnetic exchanges between the chains, ${ }^{8}$ in good agreement with the above calculations. At low magnetic field the sharp decrease of $\chi . \mathrm{T}(\mathrm{T})$ is observed below $70 \mathrm{~K}$ while magnetic ordering occurs below $\mathrm{T}_{\mathrm{N}}=6.7 \mathrm{~K}$, see S6 ; Figure S6a. A different behavior is observed above $\mathrm{H}=7 \mathrm{~T}$ with a sharp increase of $\chi$ below $\mathrm{T}_{\mathrm{N}}$, see $\chi(\mathrm{T})$ at $7 \mathrm{~T}$ in $\mathrm{S} 6$; Figure $\mathrm{S} 6 \mathrm{~b}$. This metamagnetic behavior is confirmed in $\mathrm{M}(\mathrm{H})$ curves by the sigmoid shape of the magnetization above $3.2 \mathrm{~T}$ at $2 \mathrm{~K}$ see figure $5 \mathrm{~b}$. The smooth bump of the magnetization and narrow magnetic hysteresis between 3.2 and $6 \mathrm{~T}$ is reminiscent of the metamagnetic transition in several $\mathrm{Co}^{2+}$ based systems, e.g. $\mathrm{CoH}_{2} \mathrm{P}_{2} \mathrm{O}_{7}$ (chains) and $\mathrm{Co}_{10} \mathrm{Ge}_{3} \mathrm{O}_{16}$ (3D structure). ${ }^{23}$ It corresponds to spin-flop transition, i.e. the progressive tilting of the spins until total flipping due to relatively "weak" magnetocrystalline anisotropy. Here under field, at a critical magnetic field the two sublattice magnetization deviates suddenly to a direction perpendicular to the easy magnetization direction, then a continuous rotation of the magnetic moment occurs upon increasing $\mathrm{H}$.

In compound (2), the frustrated chains with two individual Co sites are the most plausible reasons for this behavior. The observed magnetization of $4.8 \mu_{\mathrm{B}} / \mathrm{F}$.U. at $9 \mathrm{~T}$ is much lower than the expected value for a pure ferromagnetic system with two $\mathrm{Co}^{2+}$ with orbital contributions (7$8 \mu_{\mathrm{B}} /$ F.U. taking into account the significant orbital contribution, e.g. $1.38 \mu_{\mathrm{B}}$ in $\left.\mathrm{CoO}\right){ }^{26}$ This lower value is commonly found in metamagnetic cobalt chain systems ${ }^{27}$ and may be explained on the basis of Kramers $\mathrm{S}=1 / 2,<\mathrm{g}>=13 / 3$, state at low temperature due to the spin orbit coupling for $\mathrm{Co}^{2+}$. When applicable, the local magnetic moment of cobalt sites gS is expected to be reduced, e.g. $2.1 \mu_{\mathrm{B}} / \mathrm{Co}^{2+}$ in $\mathrm{Ba}_{3} \mathrm{CoNb}_{2} \mathrm{O}_{9}$ with a pronounced deviation of the Curie-Weiss slope below $50 \mathrm{~K} .{ }^{28}$ However, such situation seems excluded according to the large moments obtained in the refined magnetic structure, see below. Indeed, dealing with blocked crystals and easy axis features, one must consider the contributions of longitudinal and transverse contribution in the experimental magnetization $M=1 / 3 M_{/ /}+2 / 3 M_{\perp}$, the transverse one being poorly field dependent. ${ }^{29}$ It is most plausibly the main reason for the low experimental magnetization value. 

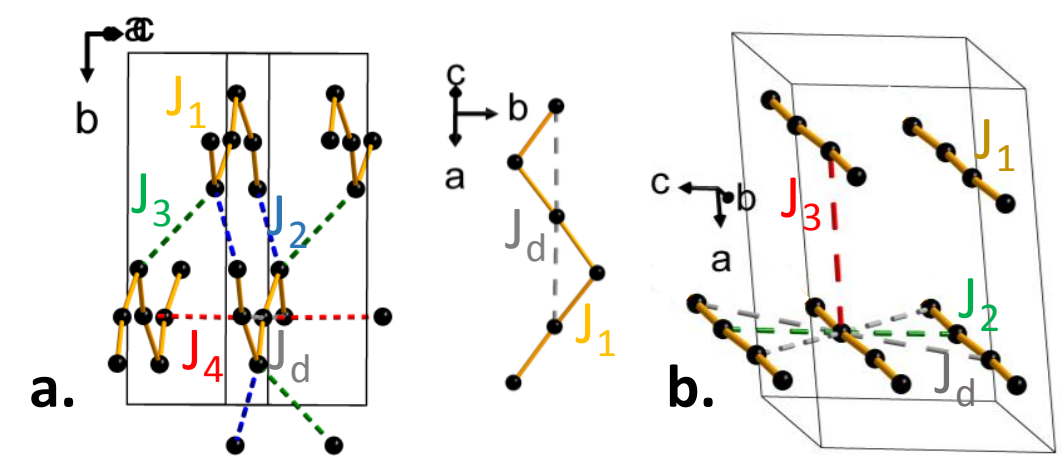

Figure 4: Main identified exchanges in (a) $\mathrm{Co}_{2} \mathrm{As}_{2} \mathrm{O}_{7} .2 \mathrm{H}_{2} \mathrm{O}$ structure and (b) $\mathrm{BaCo}_{2} \mathrm{As}_{2} \mathrm{O}_{8} .2 \mathrm{H}_{2} \mathrm{O}$ structure.
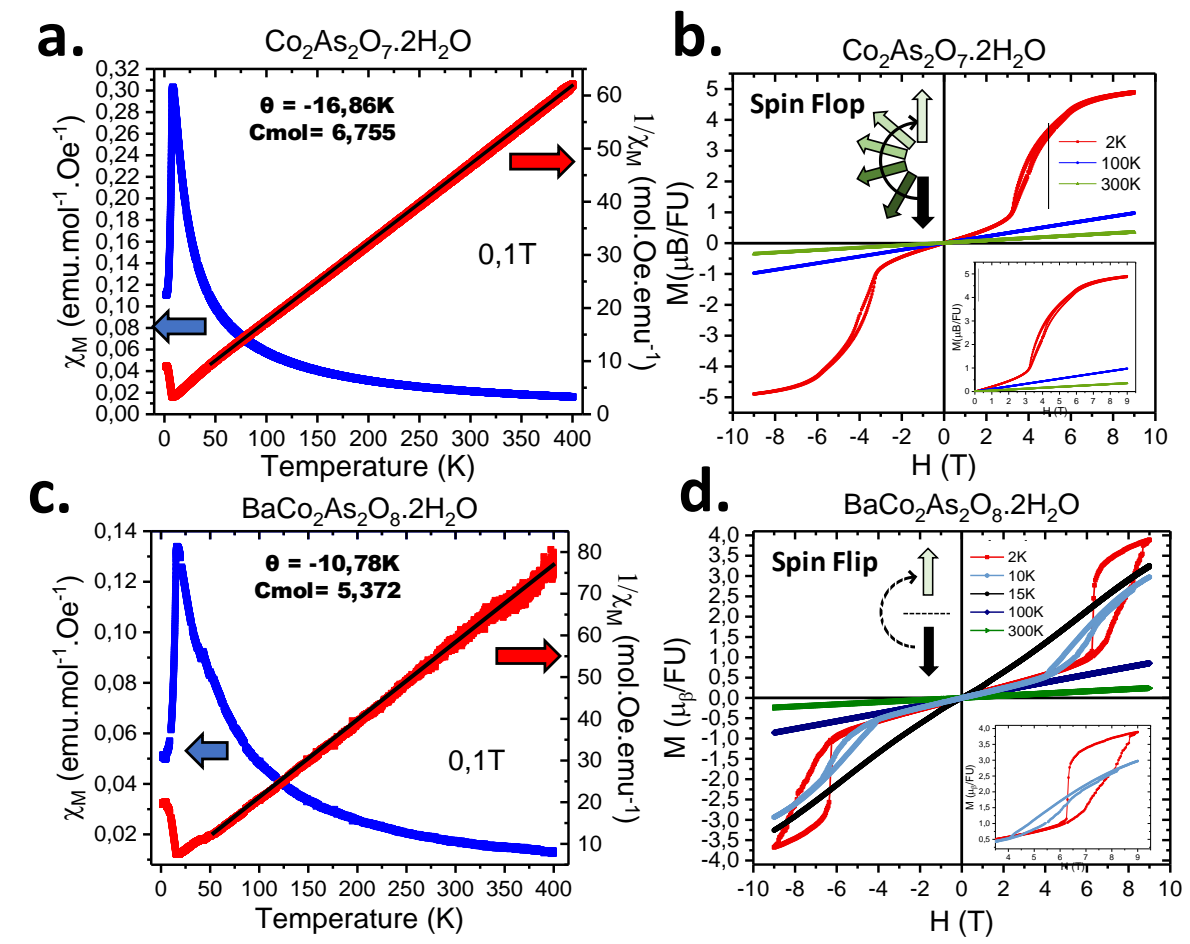

Figure 5: $\mathrm{Co}_{2} \mathrm{As}_{2} \mathrm{O}_{7} .2 \mathrm{H}_{2} \mathrm{O}$ : (a) temperature dependence of the magnetic susceptibility (in blue) and the inverse susceptibility (in red) measured at 1000Oe and (b) magnetization as a function of applied field at different temperature. (c) and (d) Same measurements for $\mathrm{BaCO}_{2} \mathrm{As}_{2} \mathrm{O}_{8} 2 \mathrm{H}_{2} \mathrm{O}$.

Compound 2 : Both phases show strong magnetic similitudes since both exhibits metamagnetic transitions associated to similar structural 1D units. In the latter the Curie-Weiss law is respected until $\sim 50 \mathrm{~K}$ leading to $\mathrm{C}=5.37 \mathrm{emu}$.K.mol $\left(\mu_{\mathrm{eff}}=4.63 \mu_{\mathrm{B}} / \mathrm{Co}\right)$ with an abrupt decay of $\chi \mathrm{T}(\mathrm{T})$ below this temperature, see $\mathrm{S} 6$; Figure S6a. The sharp susceptibility peak at $\mathrm{T}_{\mathrm{N}}$ $=15.1 \mathrm{~K}$ proves magnetic ordering as shown in Figure $5 \mathrm{c}$. The magnetization at $10 \mathrm{~K}$ is very similar to that of (1) at $2 \mathrm{~K}$ with a sigmoid shape above $\mu_{0} \mathrm{H}=4 \mathrm{~T}$ and a weak hysteresis opening assigned to spin-flop like transition see Figure $5 \mathrm{~d}$. However, on further cooling the $\mathrm{M}(\mathrm{H})$ at $\mathrm{T}$ $=2 \mathrm{~K}$ initiates a marked divergence between the field-increasing and field-decreasing branches, which highlights a certain degree of grain re-alignment or domain walls motion. In the latter branch, a sharp transition is observed at $6.2 \mathrm{~T}$, typical of spin flip metamagnetism, i.e. a sudden reorientation of the spins. Spin-flip : Here, the magnetization of the 2 sublattices remains antiparallel up to a critical field at which a sudden rotation of the magnetization towards the field direction resulting to a ferromagnetic arrangement of both sublattices. The evolution of 
the $\mathrm{M}(\mathrm{H})$ on cooling from smooth to abrupt is typical of spin flipping, see $\mathrm{FeCl}_{2} \cdot{ }^{30}$ Here again, the saturation is far from being reached leading to a magnetization value at $9 \mathrm{~T} \mathrm{M}_{9 \mathrm{~T}}=3.8$ $\mu_{\mathrm{B}} /$ F.U. Dealing with isolated crystals which behave as a polycrystalline easy-axis antiferromagnets, the transverse magnetic susceptibility $\chi_{\perp}$ is expected to lower significantly the experimental magnetization. This result should be analyzed in the light of the refined magnetic structure presented below.

Dealing with the spin-flip (2) versus spin-flop (1) transition, the linear chains and main exchanges shown in Figure $4 \mathrm{~b}$ suggest a stronger magnetocrystalline anisotropy. $\mathrm{J}_{1}$ is expected to be ferromagnetic and the linear chains favor the propagation of robust 1D-FM units. The other significant interchain exchanges are labelled $\mathrm{J}_{2}, \mathrm{~J}_{\mathrm{d}}$ (both inter-chain in plane) and $\mathrm{J}_{3}$ (along the stacking axis). Geometrical parameters along the magnetic exchange paths are listed in S5 ; Table S5d.

From $\mathrm{U}=5$ to $7 \mathrm{eV}$, reasonable $\mathrm{J}$ values with similar trends are calculated for compound (2), see S5 ; Table S5e which validate a metamagnetic scenario, in absence of frustrated chain this time. On the basis of the optimal $U$ values determined from compound (1) and reported studies, ${ }^{31}$ we will focus on the $\mathrm{J}$ values obtained for $\mathrm{U}=6 \mathrm{eV}$. Results are in good agreement with what is expected for metamagnetic transitions, as discussed above. We found within the chains ferromagnetic $\mathrm{J}_{1}(-2.06 \mathrm{~K})$. $\mathrm{J}_{2}$ is much weaker and $\mathrm{FM}$ as well $(-0.36 \mathrm{~K})$ while the diagonal inter-chain $J_{d}$ is AFM $(5.85 \mathrm{~K})$ and predominant. $J_{3}$ is found to be the weakest as expected from the disconnection of the chains trough this path $(0.23 \mathrm{~K})$. The calculated Weiss temperature $\theta_{\mathrm{c}}=-7.27 \mathrm{~K}$ falls close to the experimental value of $-10.8 \mathrm{~K}$, hence validating the calculated set of $\mathrm{J}$ values.

\section{Magnetic structures}

The onset of the magnetic ordering was confirmed through the appearance of magnetic satellites between $22 \mathrm{~K}$ and $12 \mathrm{~K}$ for compound $(2)\left(\mathrm{T}_{\mathrm{N}}=15.1 \mathrm{~K}\right)$ and between $12 \mathrm{~K}$ and $2 \mathrm{~K}$ for compound (1) $\left(\mathrm{T}_{\mathrm{N}}=6.7 \mathrm{~K}\right)$.

(1) $\mathrm{Co}_{2} \mathrm{As}_{2} \mathrm{O}_{7} .2 \mathrm{H}_{2} \mathrm{O}$ : There are two magnetic ions $\mathrm{Co} 1$ and $\mathrm{Co} 2$ in the $\mathrm{P} 2{ }_{1} / n$ unit cell, each on the Wyckoff site $4 \mathrm{e}$, decomposed into positions $(\mathrm{x}, \mathrm{y}, \mathrm{z})_{1},(-\mathrm{x}+1 / 2, \mathrm{y}+1 / 2,-\mathrm{z}+1 / 2)_{2},(-\mathrm{x},-\mathrm{y},-\mathrm{z})_{3}$, $(\mathrm{x}+1 / 2,-\mathrm{y}+1 / 2, \mathrm{z}+1 / 2)_{4}$. A symmetry analysis was performed using Basireps with the propagation vector $\mathrm{k}=\left[\begin{array}{lll}1 / 2 & 0 & 1 / 2\end{array}\right]$ able to index all magnetic satellites, Figure $6 \mathrm{a}$; the magnetic representation $\Gamma$ can be decomposed into 4 irreducible representations of dimension 1 , contained 3 times each in $\Gamma: 3 \Gamma_{1}+3 \Gamma_{2}+3 \Gamma_{3}+3 \Gamma_{4}$. Only the representations $\Gamma_{1}$ lead to calculated magnetic intensities in relation with the experimental patterns, using the same representations for $\mathrm{Co} 1$ and $\mathrm{Co} 2$.

$$
\begin{array}{ll}
\Gamma_{1}: & \mathrm{S}_{1}{ }^{\mathrm{x}}-\mathrm{S}_{2}{ }^{\mathrm{x}}+\mathrm{S}_{3}{ }^{\mathrm{x}}-\mathrm{S}_{4}{ }^{\mathrm{x}} \\
& \mathrm{S}_{1}{ }^{\mathrm{y}}+\mathrm{S}_{2}{ }^{\mathrm{y}}+\mathrm{S}_{3}{ }^{\mathrm{y}}+\mathrm{S}_{4}{ }^{\mathrm{y}} \\
& \mathrm{S}_{1}{ }^{\mathrm{z}}-\mathrm{S}_{2}{ }^{\mathrm{z}}+\mathrm{S}_{3}{ }^{\mathrm{z}}-\mathrm{S}_{4}{ }^{\mathrm{z}}
\end{array}
$$

Where $\mathrm{S}_{\mathrm{i}}{ }^{\mathrm{d}}$ is the spin component along the $\mathrm{d}$-axis of atom $\mathrm{Co}_{\mathrm{i}}$. The final refinement yields $\mathrm{R}_{\text {magn }}=$ $7.35 \%$. It gives mainly ferromagnetic spin chains with non-parallel Co1 $\left(\mathrm{M}_{2 \mathrm{~K}}=3.86 \mu_{\mathrm{B}}\right)$ and $\mathrm{Co} 2\left(\mathrm{M}_{2 \mathrm{~K}}=2.23 \mu_{\mathrm{B}}\right)$ spins and non collinear equivalent moments imposed by symmetry, see Figure $6 \mathrm{~b}$. Compared to the large moments expected from the Curie-weiss law, the Co2 moment probably pictures covalent dilution of the moment towards oxygen ligands. The magnetic space group describing the determined structure is $P_{a} 2_{1} / c$ (\#14.80) with a direct correspondence with the magnetic irreducible representation $\Gamma_{1}$. The magnetic ordering keeps the two-fold axis and the mirror plane symmetry perpendicular to the unique $b$ axis, leading to the magnetic point 
group $2 / \mathrm{m}$. This magnetic point group is non polar and does not allow for any magneto-electric effect. The tilting of spins along the chains respects the contribution of the two distinct Co1 and Co2 but pictures well the $\mathrm{J}_{1} / \mathrm{J}_{\mathrm{d}}$ competition mediating the FM effective and the intrinsic canting inherent to zigzag chains. ${ }^{32}$ The refined moments are given in Figure $6 \mathrm{c}$ and detailed in $\mathrm{S} 7$; Table S7a. In a chain, the ferromagnetic components is weak along the $a$-axis, strong along the $c$-axis and AFM along the $b$-axis, giving a net contribution of $c a .5 .8 \mu \mathrm{B} / \mathrm{F} . \mathrm{U}$ in the $(a c)$ plane at $2 \mathrm{~K}$ greater than the experimental value $\mathrm{M}_{9 \mathrm{~T}}=4.8 \mu_{\mathrm{B}} / \mathrm{F}$.U not yet saturated, due to the polycrystalline sample discussed above. The chains are AFM along $\mathrm{J}_{3}$ and $\mathrm{J}_{4}$ and $\mathrm{FM}$ along $\mathrm{J}_{1}$ and $\mathrm{J}_{2}$. According to the $\mathrm{M}(\mathrm{H})$ flop-like shape, under an external field the reversal of the spins is progressive such that the local directions of the spins as refined at $\mathrm{H}=0$ are probably lost during the reversal. This is also supported by heat capacity measurements as detailed below. In this compound, the mirror plane does not affect the chain itself, such that one could imagine chemical modifications of the non-magnetic spacers, conserving 1D-ferromagnets but assorted with different $\mathbf{J}_{2}, \mathrm{~J}_{3}, \mathrm{~J}_{4}$ within the $2 / \mathrm{m}$ ' point group (which is authorized for $\mathrm{k}=0$ ), magnetoelectric (ME) this time, with enhanced ME exchanges due to 1D macrospins.

(2) $\mathrm{BaCo}_{2} \mathrm{As}_{2} \mathrm{O}_{8} \cdot 2 \mathrm{H}_{2} \mathrm{O}$ : The magnetic structure was determined at $\mathrm{T}=12 \mathrm{~K}$ and refined at $\mathrm{T}=2$ $\mathrm{K}$ concomitantly to the magnetic structure of (1). The magnetic satellites violate the $\mathrm{C}$-centering

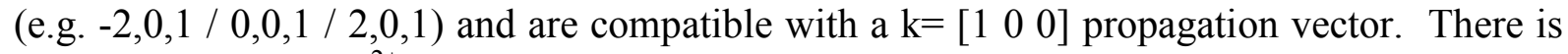
one magnetic ion $\left(\mathrm{Co}^{2+}\right)$ in the $\mathrm{C} 2 / \mathrm{c}$ unit cell, on the Wyckoff site $8 \mathrm{f}(\mathrm{x}, \mathrm{y}, \mathrm{z})$. The 4 positions in the reduced cells are $(\mathrm{x}, \mathrm{y}, \mathrm{z})_{1},(-\mathrm{x}, \mathrm{y},-\mathrm{z}+1 / 2)_{2},(-\mathrm{x},-\mathrm{y},-\mathrm{z})_{3},(\mathrm{x},-\mathrm{y}, \mathrm{z}-1 / 2)_{4}$. The magnetic symmetry analysis indicates that the magnetic representation $\Gamma$ can be decomposed into 4 irreducible representations of dimension 1, contained 3 times each in $\Gamma: 3 \Gamma_{1}+3 \Gamma_{2}+3 \Gamma_{3}+3 \Gamma_{4}$. To solve the magnetic structure, only the $\mathrm{Mx}$, My and Mz components of a single site, and the appropriate representation are therefore needed. Only the representation $\Gamma_{1}$ leads to calculated magnetic intensities in agreement the experimental data.

$$
\begin{array}{ll}
\Gamma_{1}: & \mathrm{S}_{1}{ }^{\mathrm{x}}-\mathrm{S}_{2}{ }^{\mathrm{x}}+\mathrm{S}_{3}{ }^{\mathrm{x}}-\mathrm{S}_{4}{ }^{\mathrm{x}} \\
& \mathrm{S}_{1}{ }^{\mathrm{y}}+\mathrm{S}_{2}{ }^{\mathrm{y}}+\mathrm{S}_{3}{ }^{\mathrm{y}}+\mathrm{S}_{4}^{\mathrm{y}} \\
& \mathrm{S}_{1}{ }^{\mathrm{z}}-\mathrm{S}_{2}{ }^{\mathrm{z}}+\mathrm{S}_{3}{ }^{\mathrm{z}}-\mathrm{S}_{4}{ }^{\mathrm{z}}
\end{array}
$$

Where $\mathrm{S}_{\mathrm{i}}{ }^{\mathrm{d}}$ is the component along the d-axis of atom $\mathrm{Co}_{\mathrm{i}}$. The best refinement was obtained with the representation $\Gamma_{1}\left(\mathrm{R}_{\text {magn }}=9.89 \%\right)$ at $2 \mathrm{~K}$. The refined moment for Co is $3.45 \mu_{\mathrm{B}}$ compatible with the orbital contribution deduced from the Curie-Weiss law. It shows that at 9T the magnetization $\left(\mathrm{M}_{9 \mathrm{~T}}=3.8 \mu_{\mathrm{B}} / \mathrm{F} . \mathrm{U}\right)$ is far from saturation. We note that the magnetic moments are collinear (i.e. the ferromagnetic component along the y-axis was refined to zero), while it exists in the structure a strong degree of liberty for spins to align in a canted manner with respect to the magnetic symmetry, see the model proposed for $\mathrm{BaCo}_{2}\left(\mathrm{As}_{3} \mathrm{O}_{6}\right)_{2}, 2\left(\mathrm{H}_{2} \mathrm{O}\right)^{8}{ }^{8}$ The label of oxygen atoms on Figure $6 \mathrm{~d}$ highlights the zigzag arrangement of equivalent $\mathrm{M}-\mathrm{O}$ axes along the chains directions. Then, the magnetic structure develops a robust easy magnetic axis almost parallel to the $<101>$ direction. The determined magnetic arrangement corresponds to the magnetic space group $P c 2 / c$ (\#13.74). Similarly, to the previous compound, the magnetic ordering keeps the two-fold axis and the mirror plane symmetry perpendicular to the unique $b$ axis, leading to the magnetic point group $2 / \mathrm{m}$, which is centrosymmetric. Let us consider now the possible effect of chemical modifications of the non-magnetic spacers. Here the mirror plane of the magnetic point group $2 / \mathrm{m}$ cross the chains, such that the magneto-electric $2 / \mathrm{m}$ ' involve intrinsic AFM chains except if the spins are parallel to the mirror plane. Ferromagnetic chains can also be obtained within the $2 \%$ m magneto-electric point group for spins perpendicular to the two-fold axis. These situations are possible if the $\mathrm{C}$ - centering is kept by the magnetic ordering. 
Due to spin orbit coupling the direction of the $\mathrm{Co}^{2+}$ spin is influenced by the local orbital ordering rather than crystallographic axes in isotropic ions. It was checked that in both (1) and (2) the three independent magnetic moments show a slight deviation from an equatorial square plane crossing the centers of triangular faces, in good agreement with their similar local octahedral coordination, see Figure 6e. The refined moments are given in Figure 6e and detailed in S7 ; Table S7b, Figure S7c and S7d for PND refinement at $22 \mathrm{~K}$ and $12 \mathrm{~K}$ respectively.

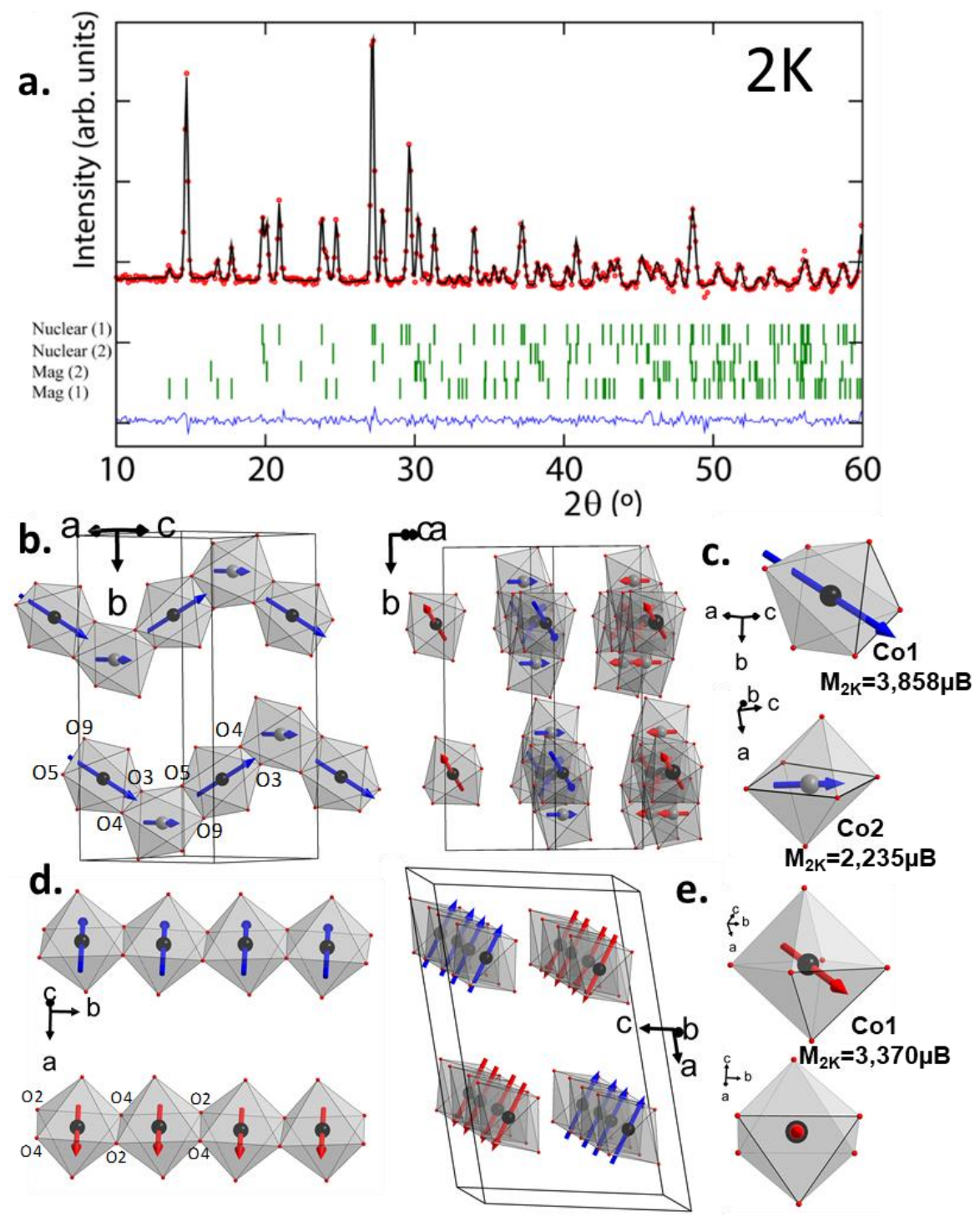

Figure 6: (a) Multiphase Rietveld Powder Neutron Diffraction refinement on a sample containing $80 \% \mathrm{Co}_{2} \mathrm{As}_{2} \mathrm{O}_{7} .2 \mathrm{H}_{2} \mathrm{O}$ and $20 \%$ BaCo $\mathrm{Cs}_{2} \mathrm{O}_{8} 2 \mathrm{H}_{2} \mathrm{O}$ performed with Winplotr Fullprof. The blue curves correspond to the difference between the experimental (red diagram) and calculated intensities (black diagram). The green vertical marks correspond top-down to $\mathrm{Co}_{2} \mathrm{As}_{2} \mathrm{O}_{7} 2 \mathrm{H}_{2} \mathrm{O}$ structural, $\mathrm{BaCo} \mathrm{As}_{2} \mathrm{O}_{8} .2 \mathrm{H}_{2} \mathrm{O}$ structural, $\mathrm{BaCo}_{2} \mathrm{As}_{2} \mathrm{O}_{8} .2 \mathrm{H}_{2} \mathrm{O}$ magnetic and $\mathrm{Co}_{2} \mathrm{As}_{2} \mathrm{O}_{7} .2 \mathrm{H}_{2} \mathrm{O}$ magnetic phases (b) Resulting magnetic structure for $\mathrm{CO}_{2} \mathrm{As}_{2} \mathrm{O}_{7} .2 \mathrm{H}_{2} \mathrm{O}(\mathrm{k}=1 / 2 ; 0 ; 1 / 2)$ with view of non collinear magnetic moment in the zigzag chains and (c) direction of the moment in the octhaedra for each of the two $\mathrm{Co}^{2+}$ sites. (d) Resulting magnetic structure for $\mathrm{BaCO}_{2} \mathrm{As}_{2} \mathrm{O}_{8} .2 \mathrm{H}_{2} \mathrm{O}(k=1 ; 0 ; 0)$ and (e) direction of the moment in the $\mathrm{Co}^{2+}$ octahedral. 


\section{Heat Capacity Measurements}

Specific heat $(\mathrm{Cp})$ versus temperature curves in the vicinity of $\mathrm{T}_{\mathrm{N}}$ are shown in Figure $7 \mathrm{a}$ and $7 \mathrm{~b}$ for some selected magnetic fields for (1) and (2) respectively. To estimate the electron-lattice specific heats we used a Debye-Einstein hybrid model for 1D Ising spin $1 / 2$ chains. ${ }^{33}$

$C_{\text {lat }}(\mathrm{T})=(1-\mathrm{x}) C_{\mathrm{D}}(\mathrm{T})+\mathrm{x} C_{\mathrm{E}}(\mathrm{T})$ with $C_{\mathrm{D}}$ and $C_{\mathrm{E}}$ the Debye and Einstein models respectively. Similar results are obtained by fitting the lattice contribution using a standard polynomial sum Clat $(\mathrm{T})=\sum_{\mathrm{i}=1 \text { to } 5} \mathrm{~A}_{\mathrm{i}}(\mathrm{T})^{\mathrm{i}} \cdot{ }^{34}$

The magnetic contribution $C_{\text {mag }}$ was obtained by subtracting this $C_{\text {lat }}$ to the $C_{\mathrm{p}}(\mathrm{T})$ data. In zero magnetic field, the magnetic entropy $S_{\mathrm{mag}}$, released with the magnetic transition was estimated to about $11.6 \mathrm{~J} /(\mathrm{mol} \mathrm{K})$ and $4.2 \mathrm{~J} /(\mathrm{mol} \mathrm{K})$ by integrating $C_{\mathrm{mag}} / \mathrm{T}$ for the (1) and (2) respectively. This accounts only for about $50 \%$ and $18 \%$ of the expected $S_{\text {mag }}=2 R \ln (4)$ for a spin $3 / 2$ system for compound (1) and (2) respectively. The rest of the entropy is spread at higher temperatures, typical for low-dimensional antiferromagnets ${ }^{25}$ but one should also note for (2) the poor accuracy on the sample weight dealing with crystals deposited one by one on the sample holder and that the crystals were not aligned when deposited.

For compound (1), the $\mathrm{Cp}$ as function of field (Fig. 7a) shows a clear suppression of the transition with field. On the contrary in (2) the transition is preserved, however the magnetic entropy is reduced to $60 \%$ of its original value. This supports the idea of spin flop versus spin flip transitions as suggested from magnetization measurements.
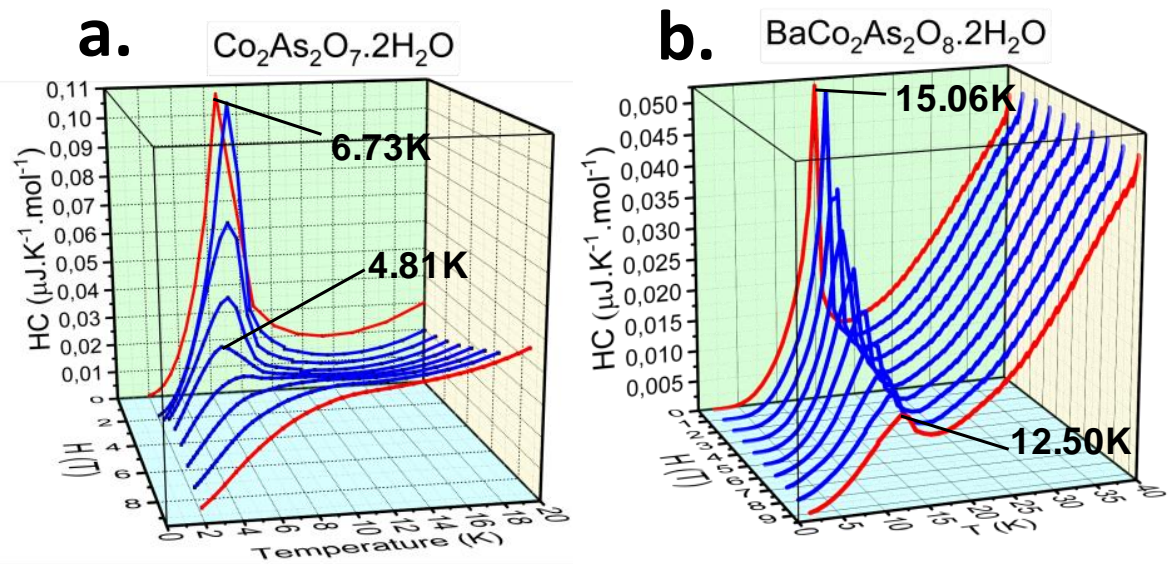

Figure 7: Heat capacity plots for $\mathrm{Co}_{2} \mathrm{As}_{2} \mathrm{O}_{7} .2 \mathrm{H}_{2} \mathrm{O}$ (a) and $\mathrm{BaCo}_{2} \mathrm{As}_{2} \mathrm{O}_{8} .2 \mathrm{H}_{2} \mathrm{O}$ (b)

\section{Conclusions}

In conclusion, we show here two systems with edge-sharing $\mathrm{Co}^{2+}$ chains, in which internal exchanges are mainly ferromagnetic leading to net $1 \mathrm{D}$ magnets. These compounds are part of an extended series of inorganic transition metal compounds with oxo-anion spacer, see S8. The exchanges between them are performed by $\mathrm{As}_{2} \mathrm{O}_{7}$ or $\mathrm{AsO}_{4}$ bridges, and relatively weak leading to metamagnetic transitions under applied magnetic field of about $4 \mathrm{~T}$ in both cases. The magnetic connections of $\mathrm{AsO}_{4}$ groups is relatively weak compared to $\mathrm{PO}_{4}$ for instance, ${ }^{18}$ mainly due to longer As-O distances and emphasize their attractive use as efficient magnetic spacers. ${ }^{34}$ The structural differences between the 1D-units themselves, i.e. linear versus zigzag chains, are responsible for different types of spin reversal under an external field, fitting well the intuitive hierarchy of magnetocrystalline anisotropy in the two compounds. Although the $\mathrm{Co}^{2+}$ spins in $\mathrm{CoO}_{6}$ octahedra exhibit Ising characters, the zigzag chains show intrinsic NN 
frustration with two individual cobalt positions playing for a non-collinear spin structure and progressive alignment within spin-flop. In the linear chains, although the group analysis allows canted structure along the chains the spin structure is collinear which highlights a robust magnetocrystalline anisotropy. This plays in favor of a sudden spin-flip transition, for which intermediate spin orientations are unfavored. In this tandem, the realization of spin-flop and spin-flip respectively picture ideally the intuitive prevision based on increasing magnetocrystalline anisotropy. However, despite the existence of non-collinear magnetic structures favouring Dzyaloshinskii-Moriya interactions, the magnetic space groups found at 0T are incompatible with magneto-electric couplings. However, one can expect that chemical substitution of the spacers (As substitution) or magnetic field favor a magnetoelectric class.

\section{ASSOCIATED CONTENT}

Supporting Information. The supporting information is available free of charge on the .... Website at DOI:

More detailed crystallographic information (with single-crystal XRD data, refined positions, anharmonic displacement parameters, interatomic distances) EDS analysis, details of DFT calculations (with values of geometrical parameters along the magnetic exchanges path, relative energies for different Ueff values and description of magnetic configurations used for $\mathrm{J}$ calculations), magnetic measurements $\chi_{M} \mathrm{~T}$ plots, powder neutron diffraction details (with refined magnetic moment values and corresponding Winplotr Plot at $22 \mathrm{~K}$ and $12 \mathrm{~K}$ ) and cell parameters of already referenced isotype compounds (PDF). X-ray crystallographic data for $\mathrm{BaCo}_{2} \mathrm{As}_{2} \mathrm{O}_{8} .2 \mathrm{H}_{2} \mathrm{O}$ CCDC 1911225 (CIF). Check-Cif Report (PDF).

\section{Notes}

The authors declare no competing financial interest.

\section{ACKNOWLEDGMENT}

This work was carried out under the framework of the LOVE-ME project supported by the ANR (Grant ANR ANR-16-CE08-0023). The Fonds Européen de Développement Régional (FEDER), CNRS, Région Hauts-de-France and Ministère de l'Education Nationale, de l'Enseignement Supérieur et de la Recherche are acknowledged for funding the X-ray diffractometers. Chevreul Institute (FR 2638), Ministère de l'Education Nationale, de l'Enseignement Supérieur et de la Recherche, Région Hauts-de-France, FEDER are acknowledged for supporting this work. We thank Laurence Burylo, Nora Djellal \& Claire Minaud at the UCCS for the help with the measurements. 


\section{REFERENCES}

(1a) Bogani, L. ; Vindigni, A. ; Sessoli, R. and Gatteschi, D. Single-Chain Magnets. J. Mater. Chem. 2008, 18, 4750-4758.

(1b) Gatteschi, D. and Vindigni, A. Single chain magnets: where to from here? Molecular Magnets: Physics and Applications. 2014, 191-220.

(2) Coldea, R.; Tennant, D. A.; Wheeler, E. M.; Wawrzynska, E.; Prabhakaran, D.; Telling, M.; Habicht, K.; Smeibidl, P. and Kiefer, K. Quantum criticality in an Ising chain: experimental evidence of emergent E8 symmetry. Science. 2010, 327, 5962, 177-180.

(3) Kobayashi, H. and Haseda, T. Metamagnetic Behavior of Ferromagnetic Linear Chain in $\mathrm{CoCl}_{2} .2 \mathrm{H}_{2} \mathrm{O}$. J. Phys. Soc. Japan. 1964, 19, 765.

(4a) Lenertz, M.; Alaria, J.; Stoeffler, D.; Colis, S.; Dinia, A.; Mentré, O.; André, G.; Porcher F. and Suard, E. Magnetic Structure of Ground and Field Induced Ordered States of Low Dimensional $\gamma-\mathrm{CoV}_{2} \mathrm{O}_{6}$. Phys. Rev. 2012, B86, 214428.

(4b) Wallington, F.; Arevalo-Lopez, A. M.; Taylor, J. W.; Stewart, J. R.; Garcia-Sakai, V.; Attfield, J. P. and Stock, C. Spin-orbit transition in $\alpha$ and $\gamma-\mathrm{CoV}_{2} \mathrm{O}_{6}$. Phys. Rev. 2015, B 92, 125116.

(4c) Markkula, M.; Arevalo-Lopez, A.M. and Attfield, J. P. Field-induced spin orders in monoclinic $\mathrm{CoV}_{2} \mathrm{O}_{6}$. Phys. Rev. 2012, B86, 134401.

(5) Canévet, E.; Grenier, B.; Klanjšek, M.; Berthier, C.; Horvatić, M.; Simonet, V. and Lejay, $\mathrm{P}$. Field-induced magnetic behavior in quasi-one-dimensional Ising-like antiferromagnet $\mathrm{BaCo}_{2} \mathrm{~V}_{2} \mathrm{O}_{8}$ : A single-crystal neutron diffraction study. Phys. Rev. 2013, B87, 054408.

(6) David, R.; Kabbour, H.; Pautrat, A. and Mentré, O. Puzzling Polymorphism of Layered $\mathrm{Ba}\left(\mathrm{CoPO}_{4}\right)_{2}$. Inorg. Chem. 2013, 52, 15, 8732-8737.

(7) David, R.; Kabbour, H.; Colis, S.; Pautrat, A.; Suard, E. and Mentré, O. Magnetization Steps Promoted by Structural Modulation in $\mathrm{BaCoX}_{2} \mathrm{O}_{7}(\mathrm{X}=\mathrm{As}, \mathrm{P})$. J. Phys. Chem. C. 2013, 117, 18190-18198.

(8) David, R.; Kabbour, H.; Colis, S. and Mentré, O. Slow Spin Dynamics between Ferromagnetic Chains in a Pure-Inorganic Framework. Inorg. Chem. 2013, 52, 13742-13750.

(9a) David, R.; Pautrat, A.; Filimonov, D.; Kabbour, H.; Vezin, H.; Whangbo, M. H. and Mentré, O. Across the Structural Re-Entrant Transition in $\mathrm{BaFe}_{2}\left(\mathrm{PO}_{4}\right)_{2}$ : Influence of the TwoDimensional Ferromagnetism. J. Am. Chem. Soc. 2013, 135,13023-13029.

(9b) Kabbour, H.; David, R.; Pautrat, A.; Koo, H. J.; Whangbo, M. H.; André, G. and Mentré, O. A Genuine Two-Dimensional Ising Ferromagnet with Magnetically Driven Re-entrant Transition Angew. Chem. 2012, 51, 11745-11749.

(10a) Wang, S. L.; Horng, J. C. and Lee, Y.H. $\mathrm{M}_{2} \mathrm{As}_{2} \mathrm{O}_{7}\left(\mathrm{H}_{2} \mathrm{O}\right)_{2}(\mathrm{M}=\mathrm{Co}$ or Ni): Hydrous Diarsenates with an Intersecting Tunnel Structure. J. Chem. Soc. 1994, 0, 1825-1829. (10b) Effenberger, H. and Pertlik, F. Comparison of the Crystal Structures of $\mathrm{Co}_{2}\left(\mathrm{X}_{2} \mathrm{O}_{7}\right)_{2} \cdot 2 \mathrm{H}_{2} \mathrm{O}$, $X=\mathrm{P}$ and As. Monatshefte fur Chemie. 1993, 124, 381-389. 
(11a) SAINT: Area-Detector Integration Software. Siemens Industrial Automation, Inc. Madison, WI, 1995.

(11b) SADABS: Area-Detector Absorption Correction. Siemens Industrial Automation, Inc. Madison, WI, 1996.

(11c) Palatinus, L. and Chapuis, G. SUPERFLIP - a computer program for the solution of crystal structures by charge flipping in arbitrary dimensions. J. Appl. Cryst. 2007, 40, 786-790. (11d) Petricek, V.; Dusek, M. and Palatinus, L. Crystallographic Computing System JANA2006: General features. Z. Kristallogr. 2014, 229, 5, 345-352.

(12) Kresse, G. Vienna Ab-Initio Simulation Package (VASP). Institut für Materialphysik: Vienna. 2012.

(13a) Kresse, G. and Joubert, D. From Ultrasoft Pseudopotentials to the Projector Augmented Wave Method. Phys. Rev. B. 1999, 59, 3, 1758-1775.

(13b) Blöchl, P.E. Projector Augmented-Wave Method. Phys. Rev. B. 1994, 50, 24, 1795317979.

(14) Perdew, J.P.; Burke, K. and Ernzerhof, M. Generalized Gradient Approximation Made Simple. Phys. Rev. Lett. 1996, 77, 18, 3865-3868.

(15a) Rodriguez-Carjaval, J. Recent advances in magnetic structure determination by neutron powder diffraction. Physica B. 1993, 192, 55.

(15b) Roisnel, T. and Rodriguez-Carjaval, J. WinPLOTR: a Windows tool for powder diffraction patterns analysis Materials Science Forum. Proceedings of the Seventh European Powder Diffraction Conference (EPDIC 7). 2000, 118-123.

(16a) Oka, J. and Kawahara, A. The Structure of Synthetic Dimagnesium Diphosphate(V) Dihydrate. Acta Cryst. 1982, B38, 3-5.

(16b) Schneider, S. and Collin, R. L. Crystal Structure of Manganese Pyrophosphate Dihydrate, $\mathrm{Mn}_{2} \mathrm{P}_{2} \mathrm{O}_{7} .2 \mathrm{H}_{2} \mathrm{O}$. Inorg. Chem. 1973, 12, 9, 2136-2139.

(16c) Brugger, J. and Berlepsch, P. Description and crystal structure of fianelite, $\mathrm{Mn}_{2} \mathrm{~V}(\mathrm{~V}, \mathrm{As}) \mathrm{O}_{7} .2 \mathrm{H}_{2} \mathrm{O}$, a new mineral from Fianel, Val Ferrera, Graubiinden, Switzerland. Am. Min. 1996, 81, 1270-1276.

(16d) Wu, C. H.; Chen, T. C. and Wang, S. L. Two Hydrous Divalent-Metal Diarsenates. Acta Cryst. 1996, C52, 1326-1329.

(16e) Stock, N.; Stucky, G. D. and Cheetham, A. K. Synthesis and Characterization of the Manganese Pyroarsenate $\mathrm{Mn}_{2} \mathrm{As}_{2} \mathrm{O}_{7} .2 \mathrm{H}_{2} \mathrm{O}$. Z. Naturforsch. 2001, 56b, 359-363.

(16f) Giesber, H. G.; Korzenski, M. B.; Pennington, W. T. and Kolis, J. W. $\mathrm{Fe}_{2} \mathrm{P}_{2} \mathrm{O}_{7}\left(\mathrm{H}_{2} \mathrm{O}\right)_{2}$. Acta Cryst. 2000, C56, 399-400.

(17a) Canévet, E.; Grenier, B.; Klanjšek, M.; Berthier, C.; Horvatić, M.; Simonet, V. and Lejay, $\mathrm{P}$. Field-induced magnetic behavior in quasi-one-dimensional Ising-like antiferromagnet $\mathrm{BaCo}_{2} \mathrm{~V}_{2} \mathrm{O}_{8}$ : A single-crystal neutron diffraction study. Phys. Rev. 2013, B87, 054408.

(17b) Mansson, M.; Prsa, K.; Sugiyama, J.; Nozaki, H.; Amato, A.; Omura, K.; Kimura, S.; and Hagiwara, M. Microscopic Magnetic Nature of the Quasi-one-Dimensional Antiferromagnet $\mathrm{BaCo}_{2} \mathrm{~V}_{2} \mathrm{O}_{8}$. Physics Procedia 30. 2012, $146-150$.

(17c) Kawasaki, Y.; Gavilano, J. L.; Keller, L.; Schefer, J.; Christensen, N. B.; Amato, A.; Ohno, T.; Kishimoto, Y.; He, Z.; Ueda, Y. and Itoh, M. Magnetic structure and spin dynamics of the quasi-one-dimensional spin-chain antiferromagnet $\mathrm{BaCo}_{2} \mathrm{~V}_{2} \mathrm{O}_{8}$. Phys. Rev. B. 2011, 83, 
0644.

(17d) Faure, Q.; Takayoshi, S.; Petit, S.; Simonet, V.; Raymond, S.; Regnault, L.P.; Boehm, M.; White, J.S.; Månsson, M.; Rüegg, C.; Lejay, P.; Canals, B.; Lorenz, T.; Furuya, S.C.; Giamarchi, T.; and Grenier, B. Topological quantum phase transition in the Ising-like antiferromagnetic spin chain $\mathrm{BaCo}_{2} \mathrm{~V}_{2} \mathrm{O}_{8}$. Nature Physics, 2018, 14, 716-722.

(18) Mentré, O.; Koo, H. J. and Whangbo M. H. Investigation of the Vanadyl Bond Ordering and Analysis of the Spin Exchange Interactions in $\mathrm{Pb}_{2} \mathrm{~V}_{3} \mathrm{O}_{9}$ and $\mathrm{Pb}_{2} \mathrm{As}_{2} \mathrm{VO}_{9}$. Chem. Mater. 2008, 20, 6929-6938.

(19a) Stock, N.; Stucky, G. D. and Cheetham, A. K. Synthesis and Characterization of the Manganese Pyroarsenate $\mathrm{Mn}_{2} \mathrm{As}_{2} \mathrm{O}_{7} .2 \mathrm{H}_{2} \mathrm{O}$. Z. Naturforsch. 2001, 56b, 359.

(19b) Aranda, M. A. G.; Bruque, S.; and Attfield, J. P. Crystal Structures and Characterization of a New Manganese(III) Arsenate, $\mathrm{MnAs}_{4} \cdot 1.2 \mathrm{H}_{2} 0$, and Manganese(II) Pyroarsenate $\mathrm{Mn}_{2} \mathrm{As}_{2} 0_{7}$. Inorg. Chem. 1991, 30, 9.

(20) Aranda, M. A. G. and Bruque, S. Characterization of Manganese(III) Orthophosphate Hydrate. Inorg. Chem. 1990, 29, 1334-1337.

(21) Assani, A.; Saadi, M.; Zriouil, M. and El Ammari, L. $\mathrm{Ni}_{2} \mathrm{Sr}\left(\mathrm{PO}_{4}\right)_{2} 2 \mathrm{H}_{2} \mathrm{O}$. Acta Cryst. 2010, E66, 86-87.

(22a) Buckley, A. M.; Bramwell, S. T. and Day, P. Structural Properties of Transition Metal Pyroarsenates $\mathrm{M}_{2} \mathrm{As}_{2} \mathrm{O}_{7}(\mathrm{M}=\mathrm{Co}, \mathrm{Mn}, \mathrm{Ni})$. J. of S. S. Chem. 1990, 86, 1-15.

(22b) Buckley, A. M. and Bramwell, S. T. The Magnetic Properties and Structures of the Transition Metal Pyroarsenates $\mathrm{M}_{2} \mathrm{As}_{2} \mathrm{O}_{7}(\mathrm{M}=\mathrm{Ni}, \mathrm{Co}, \mathrm{Mn})$. J. of S. S. Chem. 1995, 115, 229235.

(22c) Weil, M. and Stöger, B. Crystal chemistry of transition metal diarsenates $\mathrm{M}_{2} \mathrm{As}_{2} \mathrm{O}_{7}(\mathrm{M}=$ $\mathrm{Mn}, \mathrm{Co}, \mathrm{Ni}, \mathrm{Zn}$ ): variants of the thortveitite structure. Acta Cryst. 2010, B66, 603-614.

(23a) Dordevic, T. $\mathrm{BaCo}_{2}\left(\mathrm{AsO}_{4}\right)_{2}$. Acta Cryst. 2008, E64, 58-59.

(23b) Eymond, S.; Martin C. and Durif, A. Données cristallographiques sur quelques composés isomorphes du monoarseniate de Baryum-Nickel: $\mathrm{BaNi}_{2}\left(\mathrm{AsO}_{4}\right)_{2}$. Mat. Res. Bull. 1969, 4, 595600 .

(24) Whangbo, M. H.; Koo, H. J. and Dai, D. Spin exchange interactions and magnetic structures of extended magnetic solids with localized spins: theoretical descriptions on formal, quantitative and qualitative levels. Journal of Solid State Chemistry. 2003, 176, 417-481.

(25) Kovrugin,V. M.; Gordon, E. E.; Kasapbasi, E. E.; Whangbo, M. H.; Colmont, M.; Siidra, O. I.; Colis, S.; Krivovichev, S. V.; and Mentré, O. Bonding Scheme, Hydride Character, and Magnetic Paths of $\left(\mathrm{HPO}_{3}\right)_{2}-$ Versus $\left(\mathrm{SeO}_{3}\right)_{2}-$ Building Units in Solids. J. Phys. Chem. C. 2016, $120,3,1650-1656$.

(26) Radwanski, R. J. and Ropka, Z. Orbital and spin moment in CoO. ActaPhysica. 2009, 33 35, 3-6.

(27a) Yang, T.; Ju, J.; Li, G.; Yang, S.; Sun, J.; Liao, F.; Lin, J.; Sasaki, J. and Toyota, N. $\mathrm{MH}_{2} \mathrm{P}_{2} \mathrm{O}_{7}(\mathrm{M}=\mathrm{Co}, \mathrm{Ni})$ : Metamagnetic Interaction between the Zigzag Octahedral Chains. Inorg. Chem. 2007, 46, 2342-2344. 
(27b) Zhang, X. H.; Hao, Z.M. and Zhang, X.M. Spin Canting and Metamagnetism in the First Hybrid Cobalt-Hypoxanthine Open Framework with umr Topology. Chem. Eur. J. 2011, 17, $5588-5594$.

(28) Lee, M.; Hwang, J.; Choi, E. S.; Ma, J.; Dela Cruz, C. R.; Zhu, M.; Ke, X.; Dun, Z. L. and Zhou, H. D. Series of phase transitions and multiferroicity in the quasi-two-dimensional spin12 triangular-lattice antiferromagnet $\mathrm{Ba}_{3} \mathrm{CoNb}_{2} \mathrm{O}_{9}$. Phys. Rev. B. 2014, 89, 104420.

(29) Bogdanov, A. N.; Zhuravlev, A. V. and Rößler, U. K. Spin-flop transition in uniaxial antiferromagnets: Magnetic phases, reorientation effects, and multidomain states. Phys. Rev. B. 2007, 75, 094425.

(30) Fert, A. R; Carrara, P.; Lanusse, M. C.; Mischler, G. and Redoules, J. P. Transition de phase metamagnétique du bromure ferreux. J. Phys. Chem. Solids. 1973, 34, 223-230.

(31) Irfan, M.; Azam, S.; Hussain, S.; Muhammad, S. and Al-Sehemi, A.G. Effect of Coulomb interactions on optoelectronic and magnetic properties of novel $\mathrm{A}_{2} \mathrm{~V}_{2} \mathrm{O}_{7}(\mathrm{~A}=\mathrm{Fe}$ and $\mathrm{Co}$ ) compounds. Journal of Alloys and Compounds. 2018, 766, 536-545.

(32) Palii, A. V.; Reu, O. S.; Ostrovsky, S. M.; Klokishner, S. I.; Tsukerblat, B. S.; Sun, Z. M.; Mao, J. G.; Prosvirin, A. V.; Zhao, H. H. and Dunbar, K. R. A Highly Anisotropic Cobalt(II)Based Single-Chain Magnet: Exploration of Spin Canting in an Antiferromagnetic Array. J. Am. Chem. Soc. 2008, 130, 14729-14738.

(33) Hamida, Y.; Danilovic, D.; Yuen, T.; Li, K.; and Li, J. Magnetic specific heat studies of two Ising spin 1/2 chain systems M(N3)2(bpy). J. of App. Phys. 2012, 111, $07 \mathrm{~B} 332$.

(34) Ahmed, N.; Tsirlin, A. A. and Nath, R. Multiple magnetic transitions in the spin- $1 / 2$ chain antiferromagnet $\mathrm{SrCuTe}_{2} \mathrm{O}_{6}$. Phys. Rev. B. 2015, 91, 214413. 
For Table of Content Only
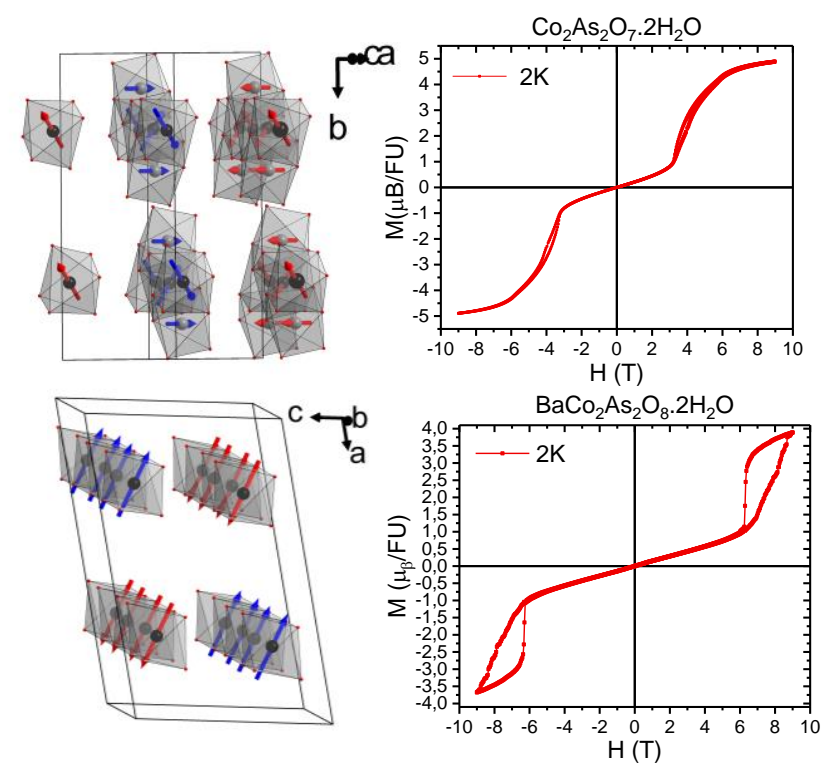

We show here the structural, thermal and magnetic characterizations of two inorganic $\mathrm{Co}^{2+}$ based systems with zig-zag versus linear decoupled 1D-chains. The resulting main magnetocrystalline anisotropies favor spin-flop and spin-flip metamagnetic transitions, respectively. 